\title{
How does trading volume affect financial return distributions?
}

\author{
Hung Do ${ }^{\mathrm{a}}$, Robert Brooks ${ }^{\mathrm{a}}$, Sirimon Treepongkaruna ${ }^{\mathrm{b}}$, Eliza $\mathrm{Wu}^{\mathrm{c} 1}$ \\ ${ }^{a}$ Department of Econometrics and Business Statistics, Monash University, Australia \\ ${ }^{b}$ Accounting and Finance, UWA Business School, The University of Western Australia, Australia \\ ${ }^{c}$ Finance Discipline Group, UTS Business School, University of Technology Sydney, Australia
}

\begin{abstract}
We assess investors' reaction to new information arrivals in financial markets by examining the relationships between trading volume and the higher moments of returns in 18 international equity and currency markets. Our volume-volatility results support extant information theories and further contribute new evidence of cross market relations between volume and volatility. We also find that the direct impact of volume on the level of negative skewness is less significant for more diversified regional portfolios. Furthermore, the negative interaction between volume and kurtosis can be explained by the differences of opinion in financial markets. We observe stronger interdependence among higher moments in reaction to significant events, but the strength is dampened by trading volume. This result is consistent with trading volume being a source of heteroskedasticity in asset returns.
\end{abstract}

Keywords: Intraday data, higher moments, information theory, fractional integrated VAR. JEL classification: C5, F3, G15.

\footnotetext{
${ }^{1}$ Corresponding author, City Campus PO Box 123, University of Technology Sydney, Broadway 2007 NSW Australia Tel: +61-2-95143905 Email address: eliza.wu@uts.edu.au
} 


\section{Introduction}

Understanding the role of trading volume in the reactions of financial market participants has long been an interesting area of research within Finance. That research contributes prominently to the knowledge of how investors process and react to unobservable information arrivals within different financial markets. A number of previous studies have highlighted the role of trading volume as a signal of informed trading. ${ }^{2}$ However, the extant research has mainly focused on the explanatory power of trading activities for return volatility. This narrow focus can limit our understanding of different aspects of market participants' reactions. While the volume - volatility analysis can explain the sensitivity of investor behaviour towards new information, different reactions towards good or bad news (captured by skewness) and levels of “over-reaction” (captured by kurtosis) may be overlooked. Hence, there may be crucial, yet not well analysed, information transmission channels driven by the relationships between trading activities and skewness/kurtosis.

Our study provides an improved understanding on the influence of trading activities on the higher moments in financial return distributions that capture different aspects of market reactions. Fundamentally, these potential interactions between trading volume and the higher moment risks (volatility, skewness and kurtosis) characterizing empirical return distributions can be explained by three relevant information-based theories in the extant literature - specifically the mixture of distributions hypothesis (MDH), the sequential arrival of information hypothesis (SAIH) and the differences of opinion hypothesis $(\mathrm{DOH})^{3}$.

\footnotetext{
${ }^{2}$ For example, Kyle (1985) emphasizes order imbalance as an indication of informed trades and Chan and Fong (2000) conclude that order imbalance can account for a substantial portion of daily stock returns. Jones et al. (1994) find that daily volatility is primarily explained by the number of trades and Giot et al. (2010) also find that the number of trades plays an important role in the volume - volatility relationship.

${ }^{3}$ The DOH hypothesis can be alternatively referred to as the dispersion of beliefs hypothesis (see Chen and Daigler, 2008) or the investor heterogeneity hypothesis (see Hutson et al., 2008). For further discussion of the three theories,
} 
For the volume - volatility relation, the theories of MDH (e.g., Clark, 1973; Epps and Epps, 1976; Tauchen and Pitts, 1983; Andersen, 1996) and DOH (e.g., Shalen, 1993; Harris and Raviv, 1993) suggest a positive contemporaneous link; whereas, a lead-lag relationship between them is added by an implication of SAIH (e.g., Copeland, 1976, 1977). Empirically, these theories have been widely tested and accepted in many studies conducted within stock or foreign exchange (FX) markets (e.g., Karpoff, 1987; Gallant et al., 1992; Chan and Fong, 2000; Kalev et al., 2004; Bjønnes et al., 2005; Bauwens et al., 2005; Chan and Fong, 2006; Giot et al., 2010). While stock market reactions are well explained by information-based trading models (e.g., Epps and Epps, 1976; Copeland, 1976; Andersen, 1996), there is also much evidence to suggest that FX trading activities also convey information for currency market participants (see Ito et al., 1998; Naranjo and Nimalendran, 2000; Evans and Lyons, 2002 among others). Similarly, equity and currency futures contract volume (amongst other futures contracts) are known to be informative for information flow in futures markets (Eastman and Lucey, 2008). However, little is known about the cross asset market (i.e., cross stock-FX market) relation between volume and volatility. Yet investor's crossmarket investment and hedging activities are likely to form the basis of an information transmission mechanism between stock and FX markets. This explanation is supported by Francis et al. (2006), who emphasize the role of FX trading activities as an economic mechanism through which information is transmitted between stock and FX markets.

In terms of the volume - skewness relationship, the DOH theory predicts that the degree of negative skewness in returns is conditional on higher trading volumes (see Hong and Stein, 2003). However, in contrast to the volume - volatility literature, empirical studies on the volume skewness relationship shows mixed results. The theory of Hong and Stein (2003) is supported by Chen et al. (2001) and Hutson et al. (2008) but not supported in Hueng and McDonald (2005) and

see Chan and Fong (2006); Girard and Biswas (2007); Chen and Daigler (2008) and Giot et al. (2010). Furthermore, the main explanations of these theories are provided in conjunction with our empirical results presented in section 4. 
Charoenrook and Daouk (2008). While a direct volume - skewness relationship is verified with firm-level data, the use of market level data shows little support for the relationship. Even though Hutson et al. (2008) provide empirical evidence on the theory postulated in Hong and Stein (2003) with national stock market data, the direct effect of volume on skewness only exists in 3 out of 11 cases. Albuquerque (2012) suggests that these conflicting results relating to skewness may be due to the different nature of skewness in firm- and aggregate market returns. While firm-level returns are always right-skewed, market-level skewness is almost always negative due to the "crosssectional phenomenon”. As firm- and market-level data clearly exhibit different degrees of diversification, it is also possible that portfolio diversification is responsible for the conflicting results. We verify the rationale of our conjecture by investigating the direct volume - skewness relationship with a particular focus on a regional portfolio context.

We further contribute to the literature by testing for the existence of volume - kurtosis interactions and whether it is consistent with the aforementioned information-based theories. New information arrival and the mechanism that incorporates information in the market are primary factors causing movements of asset prices (Andersen, 1996). Hence, the occurrence of extreme returns on the up- or down-side may be influenced subsequently. Wagner et al. (2005) support this assertion by uncovering the role played by "surprise volume” (i.e., unanticipated above-average trading activity) for volatility persistence and excess kurtosis. However, they exploit kurtosis as an additional variable in an attempt to extend knowledge about the relationship between trading volume and volatility clustering (see Lamoureux and Lastrapes, 1990), rather than emphasizing the importance of kurtosis per se. We differentiate our analysis with Wagner et al. (2005) in a sense that we focus on the importance of the volume - kurtosis relationship per se in light of the information-based theories.

Furthermore, instead of re-examining volume’s impacts on higher moments separately, we allow for the possibility of interactions among them due to several reasons. The recent financial turbulence as well as a growing integration of national economies with their own geographical 
regions and the rest of the world consistently suggests that evaluation of financial risks needs to be conducted not in isolation. We should rather allow for the possibility that one risk can interact with and spillover to amplify other risks. For example, a sequence of recent financial crises, including the Sub-prime Mortgage Crisis in 2007 in the U.S, the 2008 Global Financial Crisis and most recently, the European Sovereign Debt Crisis suggest that the assessment of financial risks needs involve a systemic approach. A higher degree of integration between national economies leads to faster and stronger contagion effects with recent evidence that a downgrade of U.S treasury bonds in mid-late 2011 significantly affected global financial markets. The contagion effects should not only highlight the transmission of risk across countries but also allow the probability of interaction between risks across markets. Empirically, some preliminary examinations using the correlation approach have revealed interdependence among higher-moment risks (e.g., Cooley et al., 1977; Gupta et al., 2004). Recently, Caporale et al. (2014) found evidence of causality-in-variance across stock and currency markets in advanced countries during the 2007-2010 crisis period. In our study, we support potential interdependence among higher-moment risks in both static (impulse response analysis) and dynamic (spillover index) approaches.

Additionally, this evidence of interconnections among higher moments motivates the need to investigate the influences of trading volume on the dynamic structure of cross-moment interrelationships. The appearance and importance of higher-moment risks have been increasingly recognized in many financial activities, such as asset pricing, value-at-risk calculations and asset allocation (see Athayde and Flôres, 2003; Mandelbrot and Hudson, 2004 among others). Therefore, such financial activities can benefit from our analysis since the results from our study can help to evaluate volatility risk, downside risk and fat-tail risk under influences of new information arrival more precisely.

We base our study on intraday data to produce a better representation and more robust estimates for higher moments of asset returns. Furthermore, the use of intraday data is also 
consistent with the aforementioned market microstructure perspective as this literature is mainly focused on intraday patterns rather than inter-day dynamics.

We find that there is an unambiguously positive and significant relationship between trading volume and realized volatility both within and cross- stock and FX markets. Spillover of higher moment risks are stronger during more volatile periods and the spillover effects of trading volume onto particularly second and fourth moments are also amplified during times of market uncertainty. However, we find that the relationship between trading volume and negative skewness is starkly different in the context of a well-diversified regional portfolio as is the dampened effect of trading volume on skewness. Lastly, we observe that the strength of the linkages amongst higher moment risks varies over time with intra-regional and global developments.

The remainder of this paper is organized as follows. Section 2 explains the construction of variables used for analysis. Section 3 outlines the econometric framework. Section 4 discusses the empirical results of the impact of trading volume on financial return distribution. Section 5 analyses the influence of trading volume on the dynamic structure of the inter-relationships among higher moments and finally, section 6 concludes.

\section{Data}

We extract 5-minute intraday data for stock market indexes and FX transactions in 18 countries from the Thomson Reuters Tick History (TRTH) database provided by the Securities Industry Research Centre of Asia-Pacific (SIRCA). The use of 5 minute intervals is suggested by Andersen et al. (2001a,b), who demonstrated that simulations of this sampling interval produce mean square errors relatively close to the optimal interval. In the FX market, we use the US dollar (USD) as the base currency against which national local currencies are priced. For stock market indexes, we use the prices denominated in local currencies. The sample extends from January 1, 
2002 to February 15, 2010. Data on weekends are excluded ${ }^{4}$. Furthermore, we base our analysis on two sub-sample periods: from January 1, 2002 to Jun 29, 2007 (the 'Stable period') and from July 2, 2007 to February 15, 2010 (the 'Volatile period') ${ }^{5}$. For the purpose of conducting regional analyses, we divide our sample countries into four regional groups, namely Latin America, Asia Pacific Emerging, Asia Pacific Developed and Western Europe. Furthermore, since the stock market is not a non-stop trading market (like the FX market), we consider a trading day as that part of the day when stock markets are open ${ }^{6}$.

We compute the 5-minute intraday returns of each market as the log change in the closing and mid prices of the stock and FX markets, respectively. For sample countries in the European Monetary Union (EMU), we use the prices of their own national currencies to calculate intraday returns before they adopted the Euro and prices denominated in Euros thereafter. The intraday returns of regional portfolios are constructed as value-weighted averages of the intraday returns of individual markets in each region where the country weights are based on their contributions to the region's aggregate gross domestic product $(\mathrm{GDP})^{7}$ :

$$
r_{n, t}=\sum_{i=1}^{q} w_{i} r_{i, n, t}
$$

\footnotetext{
${ }^{4}$ Additionally, as a result of different holidays in different countries, linear interpolation is employed to reconstruct missing data due to holidays and days with no trading activity. The interpolation method was found to be useful to deal with missing observations in time series data (see Damsleth, 1980 among others).

${ }^{5}$ Our Volatile period covers both the Sub-prime mortgage crisis in 2007 and the Global Financial Crisis in 2008.

${ }^{6}$ Hansen et al. (2005) proposes to estimate the realized volatility of a stock market for the whole day to account for the potential latent information during non-trading time. However, since our study focuses on a regional context with different countries, this methodology is not applicable because of the different trading and non-trading times in GMT in different stock markets.

${ }^{7}$ We prefer to weight countries by GDP rather than by stock market capitalization since the GDP figures are likely to be more stable compared to stock market performance with peaks and troughs.
} 
where $r_{n, t}$ denotes the $n$th 5-minute regional portfolio return during day $t, w_{i}$ is the GDP weight of market $i, r_{i, n, t}$ denotes the $n$th 5 -minute return of market $i$ during day $t$ and $q$ is the number of markets in the region.

To measure the daily realized volatility of a regional stock market portfolio, we employ the methodology shown in Andersen et al. (2003):

$$
R V_{t}=\sum_{n=1}^{N} r_{n, t}^{2}
$$

where $N$ denotes the total number of 5-minute return intervals during any trading day.

As suggested in Dacorogna et al. (2001), other higher-moment measures can also be constructed by using intraday returns. We follow the formula presented in Chen et al. (2001) to compute realized skewness. The daily realized skewness for any day $t$ is:

$$
R S_{t}=-\frac{N(N-1)^{3 / 2}\left(\sum_{n=1}^{N} r_{n, t}^{3}\right)}{(N-1)(N-2)\left(\sum_{n=1}^{N} r_{n, t}^{2}\right)^{3 / 2}}
$$

This is the negative of the third moment of returns divided by the cubed standard deviation of returns to standardise for differences in variances. The negative sign is included to make sure that an increase in the daily skewness corresponds to a stock having a more left-skewed distribution (Chen et al., 2001). Therefore, by using this formula we focus on the importance of downside risk in analysing the interdependence with other moments and trading volume.

To compute realized kurtosis, we extend the construct of measuring realized volatility. Since realized volatility is the second moment of realized returns, realized kurtosis, defined as the standardized $4^{\text {th }}$ moment of realized returns, can be calculated as:

$$
R K_{t}=\frac{\sum_{n=1}^{N} r_{n, t}^{4}}{\left(R V_{t}\right)^{2}}
$$

We employ the number of trades as a proxy for trading volume. Our choice is supported by recent studies using high frequency data (e.g., Chan and Fong, 2006; Giot et al., 2010), who find that the number of trades contains more hidden information than other proxies for volume (e.g., 
trade size and order imbalance). Theoretically, this is consistent with the existence of stealth trading, which suggests that informed traders may divide a large trade into many smaller transactions to hide their private signals. Therefore, we calculate the daily value-weighted average trading volume of a regional portfolio by summing up the total number of trades across all markets within the region over all 5 minute intervals during the day, weighted by its country’s GDP:

$$
V_{t}=\sum_{n=1}^{N} \sum_{i=1}^{m} w_{i} v_{i, n, t}
$$

where $v_{i, n, t}$ denotes the $n$th 5-minute number of trades of market $i$ during day $t, w_{i}$ is the weight of market $i$ calculated based on its country's GDP. Table 2 provides descriptive statistics for the (logged) realized volatility, realized skewness, (logged) realized kurtosis and (logged) trading volume $^{8}$ series. As expected, the mean levels of realized volatility and realized kurtosis are consistently higher in the Volatile period than in the Stable period for both stock and FX markets. In addition, the distributions of all the realized measures generally are non-normal with some level of asymmetry and excess kurtosis. However, in line with the literature (e.g., Andersen et al., 2003) the distribution of realized volatility is close to normal in many cases. Interestingly, we observe that this fact also applies to realized skewness and realized kurtosis constructed from our international dataset. The Ljung-Box statistics $(Q(20))$ confirm the significance of autocorrelation up to 20 lags in all cases for realized volatility and trading volume. The long-range dependence behaviour of realized volatility and trading volume has been previously documented in the literature (see for example, Andersen et al., 2001a, 2001b, 2003 and Fleming et al., 2011). Furthermore, we also

\footnotetext{
${ }^{8}$ Realized volatility, kurtosis and trading volume are log transformed since their non-negativity condition needs to be satisfied when they are modelled. Besides, the use of realized logarithmic volatility in empirical analysis is well supported in the literature (e.g., Andersen et al., 2001a, and Andersen et al., 2003). In addition, we use realized logarithmic kurtosis and logarithmic trading volume to achieve a similar scale for the subsequent impulse response analyses. Therefore, when we refer to realized volatility, kurtosis and trading volume in our study, they are in their natural logarithmic form.
} 
observe the existence of serial correlation in most of the cases for realized kurtosis but only in limited cases for realized skewness.

\section{Econometric framework}

\subsection{Modeling Framework for inter-relationships between trading volume and realized higher moments}

The evidence of long-range dependence in realized measures and trading volume supports the utilization of fractional integration techniques. Furthermore, in order to investigate the interdependence and feedback relationships in a system including both long- and short-memory series, a multivariate fractional process allowing for multi-memory parameters is useful. Hence, we employ the specification of a fractionally integrated vector autoregressive (FIVAR) model for our analyses.

Let a vector of jointly determined dependent variables $Y_{t}=\left(Y_{1 t}, Y_{2 t}, \ldots, Y_{K t}\right)^{\prime}$ follows a $K$ dimensional FIVAR framework ${ }^{9}$ :

$$
A(L) D(L) Y_{t}=\varepsilon_{t}, \quad t=1,2, \ldots, T .
$$

where $L$ is the lag operator and $\varepsilon_{t}$ is a $(K \times 1)$ vector of error terms, which is assumed to be white noise and multivariate normally distributed. The variance-covariance matrix of $\varepsilon_{t}$ denoted as $\Sigma_{\varepsilon}=\left\{\sigma_{i j} ; i, j=1,2, \ldots, K\right\}$ is a $(K \times K)$ positive definite matrix. The operator $A(L)=I_{K}-\sum_{i=1}^{p} A_{i} L^{i}$, where $A_{i}$ is the $(K \times K)$ matrix of coefficients and $p$ is the order of the lag polynomials in $A(L)$. All the roots of $|A(z)|=\left|I_{K}-\sum_{i=1}^{p} A_{i} z^{i}\right|=0$ are assumed to fall outside the unit circle. The operator $D(L)$ is a diagonal $(K \times K)$ matrix, $D(L)=\operatorname{diag}\left\{(1-L)^{d_{1}},(1-L)^{d_{2}}, \ldots,(1-L)^{d_{K}}\right\}$.

\footnotetext{
${ }^{9}$ According to Eq. (6), $Y_{t}$ is assumed to have no trend and drift. Hence, before modelling the realized measures and the trading volume with FIVAR, they are demeaned and detrended whenever the drift and the trend are statistically significant. Details for the existence of a trend in the realized measures and trading volume series are reported in Table 2.
} 
Given the specification in Eq. (6), we consider the realized higher moments and trading volumes as elements of the vector of endogenous variables, $Y_{t}$. We estimate all the realized measures and trading volumes for both stock and FX markets in one system ${ }^{10}$. Therefore, we have four FIVAR systems (one for each geographical region) with 8 equations in each system (3 higher moments and the trading volumes for both stock and FX market).

In addition, to investigate the inter-relationship among and between short-memory and longmemory series within a single system, we employ the Generalized Impulse Response function (GIRF, hereafter) recently developed in Do et al. (2013a, 2013b) ${ }^{11}$. The main advantage of this method is that it does not require us to determine the contemporaneous relationship among realized higher moments and trading volumes before the estimation. This plus is particularly important for our investigation since there is no clear economic guidance on the direction of instantaneous causality between our interest variables.

\subsection{Modelling framework for volume impacts on the inter-relationships among higher moments}

We model the dynamic influence of trading volume on the inter-relationship among higher moments by capturing the strength of the inter-relationship both with and without the effects of volume. When the volume impact is not controlled for, we employ a FIVAR model as shown in Eq. (6) where all realized measures form a vector of endogenous variables, $Y_{t}$. To control for the volume impacts, we consider realized measures as endogenous variables and trading volumes as exogenous variables in a FIVAR(X) framework. The specification of a FIVAR(X) model can be represented as follows ${ }^{12}$,

\footnotetext{
${ }^{10}$ We provide details of the model estimation method in the Appendix Part A1.

${ }^{11}$ A summary of the Generalized Impulse response function in a FIVAR model and its asymptotic theory is presented in Appendix part A2.

${ }^{12}$ Since $V_{t}$ is no longer an endogenous variable in the system, we employ an univariate framework in Shimotsu et al. (2005) to estimate its degree of fractional integration $\left(d_{v 1}\right.$ and $\left.d_{v 2}\right)$.
} 


$$
A(L) D(L) Y_{t}=\nabla D_{v}(L) V_{t}+\varepsilon_{t}, \quad t=1,2, \ldots, T
$$

where $\nabla$ is the $(K \times 2)$ matrix of coefficients; $D_{v}(L)=\operatorname{diag}\left\{(1-L)^{d_{v 1}},(1-L)^{d_{v 2}}\right\}$ and $V_{t}=\left(V_{1 t}, V_{2 t}\right)^{\prime}$. $V_{1 t}\left(V_{2 t}\right)$ and $d_{v 1}\left(d_{v 2}\right)$ are stock (FX) trading volume and its degree of fractional integration, respectively.

Within the FIVAR(X) system, we construct the time-varying spillover index of the interrelationship among higher moments as a proxy of its strength. This measure is motivated by some recent studies (e.g., Diebold and Yilmaz, 2009, and Bubák et al., 2011). In these papers, the evolution of volatility spillover is investigated using the spillover index, which measures the proportion of the $h$ horizontal forecast error of a variable's volatility that can be assigned to innovations in other variables within a VAR framework. Accordingly, this idea can be applied to create not only the volatility spillover index but also the index for other types of interdependence. However, instead of the orthogonalized approach developed in Diebold and Yilmaz (2009), we incorporate the generalized spillover index proposed by Diebold and Yilmaz (2012) into our FIVAR(X) model as we employ the GIRF in an early stage. To serve our dynamic analyses, the total and directional spillover indices are constructed from 1/1/2004 to 15/2/2010 by utilizing a 520day rolling window with a 1 step-ahead forecast horizon in a FIVAR(X) model ${ }^{13}$.

\footnotetext{
${ }^{13}$ Diebold and Yilmaz (2012) derived the generalized spillover index within a VAR system. However, we find it is straightforward to construct the total and directional spillover indices in a FIVAR(X) model. The total spillover index evaluates the contribution of all spillover effects from the innovations across all variables to the total forecast error variance. Therefore, this index uniquely explains the time-varying behaviour of the interdependence among all realized higher-moments. Meanwhile, the directional spillover index describes the contribution of each of the realized highermoments to the total degree of the inter-relationship among them. Further, our choice of a 520 day window is approximately equal to a 2 year period and is consistent with Shimotsu (2007) in estimating the FIVAR model. Because the choice of window size is somewhat arbitrary, we also construct the spillover indices with other window lengths. However, we find that the results remain robust to the adoption of different window lengths. Details of the spillover indices construction are provided in Appendix part A3.
} 


\section{Main Results}

\subsection{Model estimation outputs}

We report the estimated degree of fractional integration and its associated $z$-statistics as well as the optimum lag lenghts $(p)$ in Table 3 . The estimated values of memory parameters in our FIVAR systems are generally consistent with information extracted from the $Q(20)$ statistics in our preliminary analysis, which indicates that the realized volatility, kurtosis and trading volume series all strongly exhibit long memory behaviour. Furthermore, realized skewness is mostly a shortmemory series. Among the long-memory measures, realized kurtosis has the lowest degree of fractional integration. Higher values of memory parameters for realized volatility and trading volume may imply a higher degree of predictability than for realized kurtosis or skewness. This is due to greater persistence in realized volatility and trading volume. In addition, we observe higher degrees of fractional integration for all long memory measures during the Volatile period than in the Stable period for stock markets. Hence, these measures are more serially correlated during the volatile period than in the tranquil period.

The optimal lag lengths identified are reasonably short, suggesting that the long memory behaviour is adequately captured for $Y_{t}$ and the filtered series in $X_{t}\left(X_{t}=D(L) Y_{t}\right)$ are, therefore, free from long range dependence problems. We confirm this implication by inspecting the sample autocorrelation of $X_{t}$ (not shown) and check that the autocorrelation dies out quickly and then fluctuates around zero, an indication of short memory processes. In addition, many of the estimated FIVAR coefficients are statistically significant and all inverse roots of the estimate of the lag polynomial matrices in $A(L)$ are inside the unit circle, an indication of covariance stationarity ${ }^{14}$. Therefore, we can employ the GIRF to capture dynamic linkages within the FIVAR system.

\footnotetext{
${ }^{14}$ To conserve space, we do not report the estimated coefficients in the lag polynomial $A(L)$ and their inverse roots. However, the full set of results is available upon request.
} 
We define the GIRF as the spillover effect (i.e., an impulse in the ith variable, which causes a significant response of the $j$ th variable). Hence, we summarize the spillover effects from trading volume, realized volatility, skewness and kurtosis to other variables in Tables 4, 5, 6 and 7, respectively. In this study, we focus on the existence, sign and the direction of the spillover in explaining the properties of the interdependence among and between realized measures and trading volume. The existence and the sign of the spillover effects are inferred from whether the impulse responses are significantly greater or smaller than zero at the 5\% significance level. Further, as mentioned earlier, we also conduct sub-sample analyses to analyse the differences between stable and volatile periods in financial markets.

\subsection{Inter-relationships between trading volume and higher moments}

\subsubsection{The Volume - Volatility inter-relationship}

Tables 4 and 5 generally document a positive relationship between trading volume and realized volatility. Consistent with Mougoué and Aggarwal (2011), we find that there is a bidirectional spillover effect in the volume-volatility measures within the same asset markets in all cases. Our finding of a positive volume-volatility relationship is also widely supported in previous empirical studies conducted within stock and FX markets (see Melvin and Yin, 2000, Bauwens et al., 2005, Bjønnes et al., 2005 for examples of FX markets and Chen, Firth and Rui, 2001; Kalev et al., 2004, Chan et al., 2006, for examples of stock markets).

We find that stock and FX markets are highly sensitive to cross-market information flows as a bidirectional relationship is also found between trading volume in FX markets and realized volatility in stock markets in nearly all cases ${ }^{15}$. This finding corroborates with previous studies like Francis et al. (2006) as they show that FX trading activities are channels through which information is transmitted between stock and FX markets. We further uncover a unidirectional spillover from

\footnotetext{
15 The only exception is in the Western European region, in which there exists a unidirectional spillover from trading volume in FX markets to stock market realized volatility.
} 
trading volume in stock markets to realized volatility in FX markets during the volatile period. Overall, our findings indicate that stock traders do pay attention to the FX market's new information arrivals during both stable and volatile periods whilst FX traders are much more concerned about the stock market's new information arrivals during the volatile periods. In this space, we provide new insights to the literature as no study has addressed the volume-volatility relationship between stock and FX markets. Our new findings are important for better understanding information linkages across different types of asset markets.

A bidirectional relationship between trading volume and volatility is supportive of the MDH, which predicts that volume and volatility should be positively correlated since they are characterized by the same latent information flows. Meanwhile, the unidirectional spillover from trading volume to volatility is in line with the theory of heterogeneous beliefs among investors, which shows that new information arrivals in the market may lead to different interpretations between different types of traders. Therefore, traders experience different expectations regarding the fundamental values of assets, which subsequently results in greater variability in price changes (see Shalen, 1993). Furthermore, our results, drawn from an impulse response analysis, imply leadlag relations between trading volume and realized volatility, which is also consistent with the SAIH. We support the view of Chen and Daigler (2008), who consider the SAIH as being a complementary explanation for the volume-volatility relationship. Information flows may come sequentially to different traders at different times.

\subsubsection{The Volume - Skewness inter-relationship}

Empirical results shown in Tables 4 and 6 indicates that trading volume has no effect on realized skewness, thus providing a lack of support for the theoretical predictions of Hong and Stein's (2003) model at the regional level. The only exception that we observe is in the case of the Asia Pacific Emerging region during the volatile period, in which the trading volume of stock 
markets has a positive impact on the realized skewness of FX markets ${ }^{16}$. The investor heterogeneity theory of Hong and Stein (2003), used in explaining the positive impact of volume on negative skewness (i.e., higher trading volume may lead to more negative skewness of returns), is strongly supported in empirical studies using firm-level data (e.g., Chen et al., 2001). However, when the market-level data are employed, the relationship tends to disappear (e.g., Chen et al., 2001, Hueng and McDonald, 2005). More recently, Hutson et al. (2008), in using national stock market indices, provides some empirical evidence on the theory. However, the direct effect of volume on negative skewness only exists in 3 out of 11 cases, providing weak support for the theory at the national level. Therefore, based on our findings at the regional level, we conjecture that the direct influence of trading volume on negative skewness is less significant for a portfolio that is more diversified, conditional on the same market conditions. To provide some justification for our argument, we analyse the consequences of differences in investor expectations; say, investor $A$ and investor $B$ (see Hong and Stein, 2003). Assume that both investors have their own private information, where investor $B$ gets more negative signals, so that his expectation about the asset's price is lower than $A$ 's. Due to the short-sales constraint, investor $B$ will sell all of his assets and sit out of the market. Hence, there is only trade between investor $A$ and the arbitrageurs, that leads to the asset price at this time only reflecting the information of investor $A$ but not investor $B$. When some of the previously hidden signals of $B$ are revealed in the market, the asset price will drop as investor $A$ wants to get out of the market at the same price as what the arbitrageurs learn of when investor $B$ gets into the market. Hence, the more pessimistic information of $B$ is released, the more an asset's price will drop, which leads to a larger negative skewness in returns. Therefore, the higher is the degree of differences in investors' opinions, the higher the level of negative skewness, conditional on high trading volume and vice versa. Intuitively, if a portfolio is better diversified, we should

\footnotetext{
${ }^{16}$ In this specific case, our result is consistent with the theory of Hong and Stein (2003) since we emphasize on the downside risk by utilizing Eq. (3) to calculate realized skewness.
} 
expect a lower degree of differences in investors' valuations of the portfolio’s price. Accordingly, the impact of trading volume on the level of negative skewness should be less significant for a more diversified portfolio.

Regarding the opposite direction of the volume-skewness relationship, we find some (but not strong) evidence of the spillover effect from realized skewness to trading volume during the volatile period. Specifically, realized skewness has a positive impact on trading volume in terms of both within the same and cross-asset markets ${ }^{17}$. One possible explanation is that during the volatile periods, risk-averse investors tend to be more sensitive and panic in response to market downturns, which leads them to evaluate asset prices well below fundamental values. Therefore, they hope to get out of the market before the market gets worse. However, the risk-neutral arbitrageurs are not that pessimistic and are willing to buy at the price at which risk-averse investors want to step out. Consequently, the market experiences an increase in trading volume.

\subsubsection{The Volume - Kurtosis inter-relationship}

Empirical results presented in Tables 4 and 7 provide evidence of the inter-relationship between trading volume and realized kurtosis. We find a negatively bidirectional spillover effect between the two measures within the FX market during both stable and volatile periods in cases of emerging regions. Furthermore, within stock markets, a negatively unidirectional spillover effect from trading volume to realized kurtosis is observed in Latin American and Western European regions during the volatile period. We do not find significant evidence of the cross-asset market relationship between trading volume and realized kurtosis. The negative inter-relationship between trading volume and realized kurtosis is consistent with the heterogeneity of investors' beliefs

\footnotetext{
${ }^{17}$ We find a positive spillover from realized skewness of FX markets to trading volume of FX markets in cases of Asia Pacific Emerging and Developed regions; and to stock market trading volume in cases of the Asia Pacific Emerging region. Further, similar effects are also observed between realized skewness of stock markets and trading volume of FX markets in cases of Latin American and Asia Pacific Developed regions; and between realized skewness and trading volume within stock markets in the Asia Pacific Developed region.
} 
established in the literature (e.g., Shalen, 1993). When a new information flow (e.g., macroeconomic announcements) arrives in the market, different types of traders with their private signals may have different interpretations of the same information. Therefore, dispersion of beliefs appears amongst traders and leads to different asset valuations. The more uninformed (noise) traders are present in the market, the higher the degree of dispersion of beliefs among traders. Higher dispersion of beliefs, in turn, leads to a lower degree of concentration of price changes around its average value, which is revealed as a decrease in the kurtosis of the return's distribution.

\subsubsection{Non-linear granger causality between trading volume and higher realized moments}

The extant literature has identified the existence of non-linear Granger causality between trading volume and stock returns (e.g., Hiemstra and Jones, 1994; Diks and Panchenko, 2006). Hence, a check for whether there exists non-linear Granger causality between trading volume and higher moment returns is necessary to fully understand the nature of their relationship. We apply the non-parametric approach developed by Diks and Panchenko (2006) to test for potential nonlinear causality. The Diks and Panchenko (2006) non-parametric test is an over-rejection corrected version of the Hiemstra and Jones (1994) test for non-linear Granger causality.

Table 8 reports the results on whether trading volume is non-linearly Granger causing higher realized moments based on the residuals obtained from model (6). ${ }^{18}$ Table 9 reports the results on whether higher realized moments are non-linearly Granger causing trading volume. Overall, the test statistics reported are small and we fail to reject the null hypothesis in almost all cases. Hence, we can rule out non-linear Granger causality between trading volumes in currency and stock markets and return higher moments in terms of both uni-direction and bi-direction causality.

\footnotetext{
${ }^{18}$ We follow the approaches of Hiemstra and Jones (1994) and Diks and Panchenko (2006) to set the bandwidth as 1.5 and the number of lags as 1 and we reject the null hypotheses at the $5 \%$ level of significance.
} 
Individually, we find limited cases of non-linear Granger causality between trading volume and realized volatility. For example, we observe non-linear bi-directional Granger causality between FX trading volume and stock realized volatility during the volatile period in the Asia Pacific Developed and the Western European Developed markets corroborating with our linear Granger causality results to indicate that cross-asset-market linkages between stock and currency markets strengthen under turbulent financial conditions.

\subsection{Evidence of interactions among realized higher moments}

As can be seen in Table 6, we find evidence of spillover effects from realized skewness to realized volatility. The effect of FX realized skewness on the realized volatility (of both stock and FX markets) tends to be negative during the volatile period but insignificant in the stable period. Meanwhile, the stock and FX realized volatilities both respond positively to an innovation in stock market realized skewness. However, the spillover from stock market realized skewness to FX market realized volatility is only significant during the volatile period; whereas, we observe the unidirectional spillover from realized skewness to realized volatility in all cases within stock markets.

Tables 5 and 7 show strong evidence of a positively bidirectional spillover effect between realized volatility and realized kurtosis during both tranquil and volatile periods for all regions. However, we only observe this relationship within stock or FX markets but not across asset markets. Hence, the evidence overall indicates that, the volatility risk and fat-tail risk are more likely to interact with each other within the same asset markets. Furthermore, since the interaction is positive, it implies that an innovation in the return's volatility will increase the likelihood of extreme events occurring in subsequent periods. Conversely, if there is a shock to the occurrence of extreme events (captured by kurtosis), we should expect a rise in the dispersion of returns (represented by heightening realized volatility). The practical implication of our results is that investors should include different types of assets (e.g., stocks and currencies) in one portfolio to avoid the "resonance" between volatility and fat-tail risks. 


\section{Volume impacts on the inter-relationship among higher moments}

The evidence of interactions between higher moments motivates the necessity to investigate volume impacts on not only each of the higher moments separately but also the inter-relationship among all the realized moments. Additionally, based on some recent evidence of time-varying volatility spillover effects (e.g., Diebold and Yimaz, 2009; Bubák et al., 2011), we are interested in analysing the issue dynamically within the framework presented in section 3.2.

\subsection{Time-varying interdependence among realized higher moments}

We first examine the time-variations in the inter-relationship among higher moments and map the changes over time to some significant real-life events. The total spillover index, a proxy for the strength of the inter-relationship, is graphed in Figure 1 and it is evidently changing over time. On average, we observe a higher degree of interdependence in developed regions (ranging from 2028\%) in comparison with emerging regions (varying from 16-24\%). Furthermore, we find clear movements and radically different properties of the inter-relationship, corresponding to significant economic events ${ }^{19}$.

We observe that there is generally a higher degree of interaction among higher-moment risks within a geographical region when countries within the region become more integrated. The higher degree of integration between countries may be because of new policies, agreements that enhance the incorporation between national economies and the regional or international economies (e.g., the European Union enlargement plan 2004-2007, Letter of exchange establishing the Japan-ASEAN integration fund in March 2006 and the $2^{\text {nd }}$ ASEAN integration work plan 2009-2015); it can be also due to market uncertainty (e.g., the U.S sub-prime mortgage crisis in 2007, Global Financial Crisis in 2008 and the onset of the European Sovereign Debt crisis around the end of 2009). Furthermore, we also find evidence of a sudden increase in the degree of the interaction among

\footnotetext{
${ }^{19}$ We provide details of the major economic events that coincided with periods of high and low degrees of interrelationships amongst the higher-order realized moments in Figure 1.
} 
higher-moment risks associated with an arrival of pessimistic information in the market (e.g., IMF warnings about the Australian banking system in late 2006).

\subsection{Volume impacts}

After controlling for the influence of trading volume, the evolution of dynamic structure of the total spillover index is found to be consistent with discussions presented in Section 5.1. Apart from those, Figure 1 clearly reports that trading volume has an impact on the strength of the interrelationship among higher moments of returns.

In particular, trading volume nearly always decreases the total spillover indices of Asia Pacific Developed, Western European Developed and Asia Pacific Emerging region during the analysed period. More specifically, we observe from Figures 2-4 that this difference is mainly due to a decline in the proportion (\%) of spillover effects from realized kurtosis to other moments. Equivalently, this means that trading volume increases the proportion (\%) of spillover effects from realized kurtosis to itself in future periods ${ }^{20}$. Since realized kurtosis measures the occurrence of extreme returns (fat-tailedness), such increases may cause more clusters of return volatility, which last for longer periods of time. This result is consistent with Girard and Biswas (2007), who find that the volatility persistence is reduced after controlling for both expected and unexpected trading volume. Our finding can be fundamentally explained by a prominent result found in the trading volume - GARCH effect literature (initially reported in Lamoureux and Lastrapes, 1990), which indicates that trading volume is a source of heteroskedasticity (volatility clustering).

An exceptional case is the Latin American region, where we observe the inter-relationship among higher moments to increase with shocks to trading volume (Figure 1). Even though the behaviour of realized kurtosis under the volume impact is consistent with the above cases (Figure

\footnotetext{
${ }^{20}$ The spillover from one variable is built on two components: (1) spillover to all other variables in the system and (2) spillover to itself. The first (1) component is the proportion (\%) that a shock in the variable contributes to the forecast error of all others; whereas, the second (2) component is the proportion (\%) that a shock in the variable contributes to the forecast error of itself.
} 
5), significant elevations in spillover effects from realized volatilities of both stock and FX markets to other higher moments leads to this difference.

\section{Conclusion}

This paper comprehensively examines the effects of trading volume on financial return distributions in a behavioral context for regional portfolios. We assess not only how trading volume affects each higher moment but also how volume impacts on their dynamic inter-relationship. We shed new light on the volume - skewness relationship within a regional portfolio context using high-frequency data. The use of high-frequency data provides us with more robust estimates and treats higher moment return measures as observable variables, which can be appropriately modelled in a $\operatorname{FIVAR}(\mathrm{X})$ framework.

Empirical findings in our volume - volatility analysis provide support for current information based theories. Hence, we support Chen and Daigler (2008), who interpret these theories as complementary hypotheses rather than treating them as opponents. Further, we add to the literature on volume - volatility relations by also providing evidence of their positive and lead-lag relationship across stock and FX markets. Regarding the volume - skewness interaction, our regional-level analyses is not consistent with Hong and Stein's (2003) findings. Possible explanation of our findings is that the direct impact of trading volume on the level of negative skewness is less significant for a more diversified portfolio. Our explanation is based on the extension of the theory of DOH used in Hong and Stein (2003) with an intuitive expectation that a better diversified portfolio should generate a lower degree of differences in opinions regarding an asset’s fundamental value.

Lastly, we investigate the impact of trading volume on the dynamic linkages between higher

moments by using a spillover index. We find clear evidence that the strength of the linkages between higher moments is affected by trading volume. The level of the inter-relationship in Asia Pacific Developed, Western European Developed and Asia Pacific Emerging region decreases with shocks to trading volume. This is mainly due to a decline in the proportion (\%) of spillover from 
realized kurtosis to the lower moments; or equivalently, an increase in the proportion (\%) of spillover from realized kurtosis to itself in future periods. This has policy implications for financial market regulations (e.g. the imposition of short-selling bans) that affect trading volume and in turn, financial return distributions and risks. We leave the investigation of short-selling activities on volume spillover for future research. 


\section{REFERENCES}

Albuquerque, R. (2012). Skewness in stock returns: Reconciling the evidence on firm versus aggregate returns. Review of Financial Studies, 25, 1630-73.

Andersen, T. G. (1996). Return volatility and trading volume: an information flow interpretation of stochastic volatility. Journal of Finance, 51, 169-204.

Andersen, T. G., Bollerslev, T., Diebold, F. X., \& Labys, P. (2003). Modeling and forecasting realized volatility. Econometrica, 71, 579-625.

Andersen, T., Bollerslev, T., Diebold, F. X., \& Ebens, H. (2001a). The distribution of realized stock return volatility. Journal of Financial Economics, 61, $43-76$.

Andersen, T., Bollerslev, T., Diebold, F. X., \& Labys, P. (2001b). The distribution of realized exchange rate volatility. Journal of the American Statistical Association, 96, 42-55.

Athayde, G., \& Flôres, R. (2003). Incorporating skewness and kurtosis in portfolio optimization: A multidimensional efficient set. In S. Satchell, \& A. Scowcroft, Advances in Portfolio Construction and Implementation (pp. 243-257). Butterworth-Heinemann Finance.

Bauwens, L., Omrane, W. B., \& Giot, P. (2005). News announcements, market activity and volatility in the euro/dollar foreign exchange market. Journal of International Money and Finance, 24, 11081125.

Bjønnes, G. H., Rime, D., \& Solheim, H. O. (2005). Liquidity provision in the overnight foreign exchange market. Journal of International Money and Finance, 24, 175-196.

Bubák, V., Kočenda, E., \& Žikeš, F. (2011). Volatility transmission in emerging European foreign exchange markets. Journal of Banking and Finance, 35, 2829-41.

Caporale, G.M., Hunter, J., \& Ali, F.M. (2014). On the linkages between stock prices and exchange rates. International Review of Financial Analysis 33, 87-103.

Chan, C. C., \& Fong, W. M. (2006). Realized volatility and transactions. Journal of Banking and Finance, 30, 2063-2085.

Chan, K., \& Fong, W. M. (2000). Trade size, order imbalance, and the volatility-volume relation. Journal of Financial Economics, 57, 247-273.

Charoenrook, A., \& Daouk, H. (2008). Conditional skewness of aggregate market returns. Finance International Meeting AFFI-EUROFIDAI. Paris.

Chen, J., Hong, H., \& Stein, J. C. (2001). Forecasting crashes: trading volume, past returns, and conditional skewness in stock prices. Journal of Financial Economics, 63, 345-381.

Chen, G., Firth, M., \& Rui, O. M. (2001). The dynamic relation between stock returns, trading volume, and volatility. The Financial Review, 36, 143-174.

Chen, Z., \& Daigler, R. T. (2008). An examination of the complementary volume-volatility information theories. Journal of Futures Markets, 28, 963-992.

Clark, P. K. (1973). A subordinated stochastic process model with finite variance for speculative prices. Econometrica, 41, 135-155.

Cooley, P. L., Roenfeldt, R. L., \& Modani, N. K. (1977). Interdependence of market risk measures. Journal of Business, 50, 356-363.

Copeland, T. E. (1976). A model of asset trading under the assumption of sequential information arrival. Journal of Finance, 31, 1149-1168. 
Copeland, T. E. (1977). A probability model of asset trading. Journal of Financial and Quantitative Analysis, 12, 563-578.

Dacorogna, M. M., Gencay, R., Muller, U. A., Olsen, R. B., \& Pictet, O. V. (2001). An Introduction to High-Frequency Finance. London: Academic Press.

Damsleth, E. (1980). Interpolating missing values in a time series. Scandinavian Jounal of Statistics, theory and application, 7, 33-39.

Diebold, F. X., \& Yilmaz, K. (2009). Measuring financial asset return and volatility spillovers, with application to global equity markets. The Economic Journal(119), 158-171.

Diebold, F. X., \& Yilmaz, K. (2012). Better to give than to receive: Predictive directional measurement of volatility spillovers. International Journal of Forecasting, 28, 57-66.

Diks, C., Panchenko, V. (2006). A new statistic and practical guidelines for nonparametric Granger causality testing. Journal of Economic Dynamics \& Control 30, 1647-1669.

Do, H. X., Brooks, R. D., \& Treepongkaruna, S. (2013a). Generalized impulse response analysis in a fractionally integrated vector autoregressive model. Economics Letters, 118, 462-465.

Do, H. X., Brooks, R. D., \& Treepongkaruna, S. (2013b). Asymptotic distribution of impulse response functions of a fractionally integrated Vector Autoregressive model. Unpublished manuscript.

Eastman, A. \& Lucey, B. (2008), Skewness and Asymmetry in Futures Returns and Volumes. Applied Financial Economics 18, 777-800.

Epps, T. W., \& Epps, M. L. (1976). The stochastic dependence of security price changes and transaction volumes: implications for the mixture of distributions hypothesis. Econometrica, 44, 305-321.

Evans, M. D., \& Lyons, R. K. (2002). Order flow and exchange rate dynamics. Journal of Political Economy, 110, 170-180.

Fleming, J., \& Kirby, C. (2011). Long memory in volatility and trading volume. Journal of Banking and Finance, 35, 1714-1726.

Francis, B. B., Hasan, I., \& Hunter, D. M. (2006). Dynamic relations between international equity and currency markets: the role of currency order flow. Journal of Business, 79, 219-258.

Gallant, R. A., Rossi, P. E., \& Tauchen, G. (1992). Stock prices and volume. Review of Financial Studies, 5, 199-242.

Girard, E., \& Biswas, R. (2007). Trading volume and market volatility: developed versus emerging stock markets. The Financial Review, 42, 429-459.

Giot, P., Laurent, S., \& Petitjean, M. (2010). Trading activity, realized volatility and jumps. Journal of Empirical Finance, 17, 168-175.

Gupta, B., \& Chatiras, M. (2004). The interdependence of managed futures risk measures. In G. N. Gregoriou, V. N. Karavas, F.-S. Lhabitant, \& F. Rouah, Commodity trading advisors: risk, performance analysis, and selection (pp. 203-219). New Jersey: John Willey and Sons, Inc.

Hansen, P. R., \& Lunde, A. (2005). A realized variance for the whole day based on intermittent highfrequency data. Journal of Financial Econometrics, 3, 525-554.

Harris, M., \& Raviv, A. (1993). Differences of opinion make a horse race. Review of Financial Studies, 6 , 473-506.

Hiemstra, C., Jones, J.D. (1994). Testing for linear and nonlinear Granger causality in the stock price-volume relation. Journal of Finance 49, 1639-1664. 
Hong, H., \& Stein, J. C. (2003). Differences of opinion, short-sales constraints, and market crashes. The Review of Financial Studies, 16, 487-525.

Hueng, C. J., \& McDonald, J. B. (2005). Forecasting asymmetries in aggregate stock market returns: Evidence from conditional skewness. Journal of Empirical Finance, 12, 666-685.

Hutson, E., Kearney, C., \& Lynch, M. (2008). Volume and skewness in international equity markets. Journal of Banking and Finance, 32(7), 1255-1268.

Ito, T., Lyons, R. K., \& Melvin, M. T. (1998). Is there private information in the FX market? The Tokyo experiment. Journal of Finance, 53, 1111-30.

Jones, C. M., Kaul, G., \& Lipson, M. L. (1994). Transactions, volume, and volatility. Review of Financial Studies, 7, 631-651.

Kalev, P. S., Liu, W.-M., \& Pham, P. K. (2004). Public information arrival and volatility of intraday stock returns. Journal of Banking and Finance, 28, 1441-1467.

Karpoff, J. M. (1987). The relation between price changes and trading volume: A survey. Journal of Financial and Quantitative Analysis, 22, 109-126.

Kyle, A. S. (1985). Continuous auctions and insider trading. Econometrica, 53, 1315-1336.

Lamoureux, C. G., \& Lastrapes, W. D. (1990). Heteroskedasticity in stock return data: volume versus GARCH effects. Journal of Finance, 45, 221-229.

Mandelbrot, B. B., \& Hudson, R. L. (2004). The (mis) behaviour of markets: a fractal view of risk, ruin and reward. London: Profile.

Melvin, M., \& Yin, X. (2000). Public information arrival, exchange rate volatility, and quote frequency. The Economic Journal, 110, 644-661.

Mougoué, M., \& Aggarwal, R. (2011). Trading volume and exchange rate volatility: Evidence for the sequential arrival of information hypothesis. Journal of Banking and Finance, 35, 2690-2703.

Naranjo, A., \& Nimalendran, M. (2000). Government intervention and adverse selection costs in Foreign Exchange markets. Review of Financial Studies, 13, 453-77.

Pesaran, B., \& Pesaran, M. H. (2009). Times series econometrics: using Microfit 5.0. Wiltshire: Oxford University Press.

Shalen, C. (1993). Volume, volatility, and the dispersion of beliefs. The Review of Financial Studies, 6, 405-434.

Shimotsu, K. (2007). Gaussian semiparametric estimation of multivariate fractionally integrated processes. Journal of Econometrics, 137, 177-310.

Shimotsu, K., \& Phillips, P. C. (2005). Exact local Whittle estimation of fractional integration. The Annals of Statistics, 33, 1890-1933.

Tauchen, G. E., \& Pitts, M. (1983). The price variability-volume relationship in speculative markets. Econometrica, 51, 485-505.

Wagner, N., \& Marsh, T. A. (2005). Surprise volume and heteroskdasticity in equity market returns. Quantitative Finance, 5, 153-168. 


\section{APPENDICES}

\section{Part A - Methodologies}

\section{A1. Estimation of a FIVAR model}

Due to high dimensional systems as well as large sample size in our study, we employ the two-step estimation method, whereby the memory parameters are consistently determined in the first step and the estimation of remaining parameters is subsequently performed with standard econometric techniques. In the first stage, we estimate the memory parameters under a multivariate framework proposed by Shimotsu (2007) to efficiently capture possible dependencies among them.

After consistently estimating $d$, we transform $Y_{t}$ to $X_{t}=\left(x_{1 t}, x_{2 t}, \ldots, x_{K t}\right)^{\prime}$ by applying the relationship:

$$
x_{i t}= \begin{cases}(1-L)^{d_{i}} y_{i t} & \text { if } d_{i}<\frac{1}{2} \\ (1-L)^{d_{i}-1}(1-L) y_{i t} & \text { if } \frac{1}{2}<d_{i}<\frac{3}{2}\end{cases}
$$

Operationally, we can generate the term $(1-L)^{-d_{j}}$ with the following binomial expansion:

$$
(1-L)^{-d_{j}}=\sum_{i=0}^{\infty} \frac{\Gamma\left(i+d_{j}\right)}{\Gamma\left(d_{j}\right) \Gamma(i+1)} L^{i}=\sum_{i=0}^{\infty} \psi_{i}^{\left(d_{j}\right)} L^{i}
$$

where $\Gamma\left(\right.$.) is the gamma function; $\psi_{0}^{(0)}=1$, and $\psi_{i}^{(0)}=0$, for $i \neq 0$.

Then, we apply Ordinary Least Squares (OLS) equation-by equation to estimate the following unrestricted Vector Autoregressive (VAR) model:

$$
A(L) X_{t}=\varepsilon_{t}
$$

So, model specification (10) is stationary if all the roots of the estimated polynomial $|A(z)|=0$ are outside the unit circle. We determine the orders of the lag polynomials $(p)$ in $A(L)$ based on the lowest AIC.

\section{A2. Generalized Impulse Response function in a FIVAR model}


According to Do et. al (2013a), the GIRF for FIVAR at the horizon $h$ can be expressed by,

$$
\Theta_{h}^{g}=\Phi_{h} \Sigma_{\varepsilon} \Xi=\Phi_{h} B \quad h=0,1,2, \ldots
$$

where $\Xi$ is a diagonal $(K \times K)$ matrix formed as, $\Xi=\operatorname{diag}\left\{\sigma_{11}^{-1 / 2}, \sigma_{22}^{-1 / 2}, \ldots, \sigma_{K K}^{-1 / 2}\right\}$. And,

$$
\Phi_{h}= \begin{cases}\sum_{i=0}^{h} \Psi_{i}^{(d)} \Pi_{h-i} & h=1,2, \ldots \\ \prod_{0} & h=0\end{cases}
$$

where $\Psi_{i}^{(d)}$ is the diagonal $(K \times K)$ matrix with $\psi_{i}^{\left(d_{j}\right)}$ as the $j^{\text {th }}$ diagonal element, and the $(K \times K)$ matrices $\Pi_{i}$ can be computed recursively using the relationship,

$$
\Pi_{i}=\left\{\begin{array}{lr}
\sum_{j=1}^{i} \Pi_{i-j} A_{j} & i=1,2, \ldots p \\
\sum_{j=1}^{p} \Pi_{i-j} A_{j} & i>p
\end{array}\right.
$$

where $\Pi_{0}=I_{K}$.

In addition, for statistical inference on the existence of the relationship, we employ the asymptotic theory of the GIRF derived in Do et al. (2013b).

Let $\hat{\Theta}_{h}^{g}$ denotes the estimator of the true impulse response matrix $\Theta_{h}^{g}$, and,

$$
\begin{gathered}
H_{h}:=\left(B^{\prime} \otimes I_{K}\right)\left(\sum_{i=0}^{h-1} \sum_{j=0}^{h-i-1} J\left(A^{\prime}\right)^{h-i-1-j} \otimes \Psi_{i}^{(d)} \Pi_{j}\right), \\
\bar{H}_{h}:=\left(\Xi^{3} \otimes \Phi_{h} \Sigma_{\varepsilon}\right) S_{K} D_{K}+\left(\Xi \otimes \Phi_{h}\right) D_{K},
\end{gathered}
$$

where $\otimes$ denotes the Kronecker product, $D_{K}$ is the $\left(K^{2} \times K(K+1) / 2\right)$ duplication matrix, $S_{K}$ is defined in Do et al. (2013b) as the $\left(K^{2} \times K^{2}\right)$ diagonal-stacking matrix, $S_{K}=E_{K} E_{K}^{\prime} . E_{K}$ is a $\left(K^{2} \times K\right)$ matrix of 0 and 1 represented as, ${ }_{\left(K_{K}^{2} \times K\right)}^{E_{K}}=\left[e_{1} e_{1}^{\prime}, e_{2} e_{2}^{\prime}, \ldots, e_{K} e_{K}^{\prime}\right]^{\prime}$, where $e_{i}$ is the $(K \times 1)$ vector with 1 in the $i^{\text {th }}$ element and 0 elsewhere.

Matrix $A$ and $J$ are represented as, 


$$
\underset{(K p \times K p)}{A}:=\left[\begin{array}{ccccc}
A_{1} & A_{2} & \cdots & A_{p-1} & A_{p} \\
I_{K} & 0 & \cdots & 0 & 0 \\
0 & I_{K} & \cdots & 0 & 0 \\
\vdots & \vdots & \ddots & \vdots & \vdots \\
0 & 0 & \cdots & I_{K} & 0
\end{array}\right], \underset{(K \times K p)}{J}:=\left[I_{K}: 0: \cdots: 0\right],
$$

Furthermore, we denote,

$$
\Sigma_{\hat{\alpha}}=\Gamma_{X}^{-1} \otimes \Sigma_{\varepsilon},
$$

where $\Gamma_{X}$ can be obtained from,

$$
\begin{gathered}
\operatorname{vec} \Gamma_{X}=\left(I_{(K p)^{2}}-A \otimes A\right)^{-1} \operatorname{vec} \Sigma_{U}, \\
\underset{(K p \times K p)}{\sum_{U}}=\left[\begin{array}{cc}
\Sigma_{\varepsilon} & 0 \\
0 & 0
\end{array}\right],
\end{gathered}
$$

and,

$$
\Sigma_{\hat{\sigma}}=2 D_{K}^{+}\left(\Sigma_{\varepsilon} \otimes \Sigma_{\varepsilon}\right) D_{K}^{+\prime},
$$

where $D_{K}^{+}=\left(D_{K}^{\prime} D_{K}\right)^{-1} D_{K}^{\prime}$ is the Moore-Penrose inverse of the duplication matrix $D_{K}$.

With these notations, the asymptotic distribution of the generalized impulse responses for a FIVAR can be written as,

$$
\sqrt{T} \operatorname{vec}\left(\hat{\Theta}_{h}^{g}-\Theta_{h}^{g}\right) \stackrel{d}{\longrightarrow} N\left(0, H_{h} \Sigma_{\hat{\alpha}} H_{h}^{\prime}+\bar{H}_{h} \Sigma_{\hat{\sigma}} \bar{H}_{h}^{\prime}\right) \quad h=1,2, \ldots .
$$

\section{A3. The spillover index in a FIVAR(X) model}

Similar to the idea of a generalized variance decomposition of a VAR model (see Pesaran and Pesaran, 2009, section 22.6.2), we can easily obtain the $\{(i, j), i, j=1,2, \ldots, K\}$ element in the matrix of the $h$ step-ahead variance decomposition of a FIVAR(X) process using the generalized approach as follows,

$$
\theta_{i j}^{g}(h)=\frac{\sigma_{j j}^{-1} \sum_{l=0}^{h-1}\left(e_{i}^{\prime} \Phi_{l} \Sigma_{\varepsilon} e_{j}\right)^{2}}{\sum_{l=0}^{h-1}\left(e_{i}^{\prime} \Phi_{l} \Sigma_{\varepsilon} \Phi_{l}^{\prime} e_{i}\right)}
$$


This variance decomposition matrix can be subsequently used to derive the spillover indices as presented in Diebold and Yilmaz (2012). The total spillover index is computed as,

$$
S^{g}(h)=\frac{\sum_{\substack{i, j=1 \\ i \neq j}}^{K} \tilde{\theta}_{i j}^{g}(h)}{K} \times 100
$$

where $\tilde{\theta}_{i j}^{g}(h)$ is the $(i, j)$ element of the variance decomposition matrix normalized by the row sum,

$$
\tilde{\theta}_{i j}^{g}(h)=\frac{\theta_{i j}^{g}(h)}{\sum_{j=1}^{K} \theta_{i j}^{g}(h)}
$$

The total spillover index evaluates the contribution of all spillover effects from the innovations across all variables to the total forecast error variance. However, as this index cannot separately identify the contribution of spillover from shocks in each variable, we also calculate the directional spillover index to investigate the contribution of each of the realized higher-moments to the total degree of the inter-relationship among them. The directional spillover from variable $i$ to all other variables in the system can be estimated as,

$$
S_{-i}^{g}(h)=\frac{\sum_{\substack{j=1 \\ j \neq i}}^{K} \tilde{\theta}_{j i}^{g}(h)}{K} \times 100
$$


Part B - Tables and Figures

Table 1: Regions, country weights and GMT trading time

\begin{tabular}{llcccc}
\hline \hline \multirow{2}{*}{ Regions } & Countries & Average & Weight & \multicolumn{2}{c}{ Trading time (GMT) ${ }^{(2)}$} \\
\cline { 5 - 6 } Latin America & & GDP & Value & Standard time & DST \\
\hline & Argentina & 295 & 0.14 & $14: 00-21: 00$ & - \\
& Brazil & 1,558 & 0.73 & $13: 00-20: 00$ & $12: 00-19: 00$ \\
& Chile & 169 & 0.08 & $13: 30-21: 00$ & $12: 30-20: 00$ \\
& Peru & 121 & 0.06 & $13: 30-21: 00$ & - \\
\hline \multirow{3}{*}{ Asian Pacific Emerging } & Indonesia & 511 & 0.33 & $2: 30-9: 00$ & - \\
& Malaysia & 199 & 0.13 & $1: 00-9: 00$ & - \\
& Philippines & 163 & 0.11 & $1: 30-4: 00$ & - \\
& Taiwan & 395 & 0.26 & $1: 00-5: 30$ & - \\
& Thailand & 262 & 0.17 & $3: 00-9: 30$ & - \\
\hline \multirow{3}{*}{ Asian Pacific Developed } & Australia & 962 & 0.14 & $0: 00-6: 00$ & $23: 00-5: 00$ \\
& Hong Kong & 209 & 0.03 & $2: 00-8: 00$ & - \\
& Japan & 4,830 & 0.68 & $0: 00-6: 00$ & - \\
& Korea & 956 & 0.13 & $0: 00-6: 00$ & - \\
& New Zealand & 126 & 0.02 & $22: 00-4: 00$ & - \\
\hline \hline \multirow{2}{*}{ Western Europe } & Austria & 373 & 0.06 & $8: 30-16: 30$ & $7: 30-15: 30$ \\
& France & 2,571 & 0.38 & $8: 00-16: 30$ & $7: 00-15: 30$ \\
& Germany & 3,304 & 0.49 & $8: 00-16: 30$ & $7: 00-15: 30$ \\
& Switzerland & 469 & 0.07 & $8: 00-16: 30$ & $7: 00-15: 30$ \\
\hline
\end{tabular}

Note: (1) The average GDP of each country is computed by using its GDP (in billion USD) from 2006 to 2010 . We download most of the GDP data from the World Bank, except for Taiwan which we sourced from the Australian Government’s - Department of Foreign Affairs and Trade.

(2) We convert the trading times of each stock market to GMT time. In addition, DST denotes the Daylight Saving Time. 
Table 2a: Descriptive Statistics for the Realized measures and trading volume of Foreign Exchange markets

\begin{tabular}{|c|c|c|c|c|}
\hline \multicolumn{5}{|c|}{ Stable period } \\
\hline Mean & Std. Dev & Skewness & Kurtosis & Q-stat(20) \\
\hline
\end{tabular}

\begin{tabular}{|c|c|c|c|c|}
\hline \multicolumn{5}{|c|}{ Volatile period } \\
\hline Mean & Std. Dev & Skewness & Kurtosis & Q-stat(20) \\
\hline
\end{tabular}

Panel A: Descriptive statistics for the Realized Volatility estimates

\begin{tabular}{|c|c|c|c|c|c|c|c|c|c|c|}
\hline Latin America ( $\neq, \ddagger$ ) & -10.00 & 1.05 & -0.45 & 6.97 & $5168.4 * * *$ & -9.64 & 1.23 & -1.69 & 13.85 & $1640.5 * * *$ \\
\hline Asian Pacific Emerging ( & -11.89 & 1.69 & 1.46 & 5.55 & $13547 * * *$ & -10.54 & 2.27 & 0.77 & 2.24 & $7886.5^{* * *}$ \\
\hline Asian Pacific Developed (†, 竍) & -11.36 & 0.84 & 0.29 & 4.08 & $674.4 * * *$ & -10.80 & 0.93 & 0.36 & 3.40 & $836.5 * * *$ \\
\hline Western Europe ( & -10.60 & 0.73 & 0.04 & 3.80 & $2852.8^{* * *}$ & -10.27 & 0.93 & -0.06 & 3.78 & $3770.3 * * *$ \\
\hline
\end{tabular}

Panel B: Descriptive statistics for the Realized Skewness estimates

\begin{tabular}{|c|c|c|c|c|c|c|c|c|c|c|}
\hline Latin America & 0.09 & 1.57 & -0.13 & 7.19 & $31.2 *$ & 0.16 & 2.15 & 0.03 & 4.89 & 21.69 \\
\hline Asian Pacific Emerging & 0.24 & 1.96 & 0.54 & 5.96 & $36.1 * *$ & -0.09 & 2.25 & 0.73 & 6.41 & 21.59 \\
\hline Asian Pacific Developed & -0.18 & 4.34 & -0.02 & 2.90 & $32.1 * *$ & -0.13 & 4.30 & -0.08 & 2.85 & 17.94 \\
\hline Western Europe & 0.27 & 2.81 & 0.15 & 4.07 & 18.4 & 0.11 & 3.07 & 0.08 & 3.34 & $31.1^{*}$ \\
\hline \multicolumn{11}{|c|}{ Panel C: Descriptive statistics for the Realized Kurtosis estimates } \\
\hline Latin America ( $\neq,+\neq)$ & -2.57 & 0.73 & 0.94 & 3.37 & $154.7 * * *$ & -2.46 & 0.84 & 0.64 & 2.56 & $52.6 * * *$ \\
\hline Asian Pacific Emerging ( & -2.27 & 0.76 & 0.42 & 2.69 & $457.64 * * *$ & -1.97 & 0.70 & 0.42 & 2.67 & $218.4 * * *$ \\
\hline Asian Pacific Developed & -1.98 & 1.11 & 0.11 & 1.58 & $42.4 * * *$ & -1.98 & 1.12 & 0.04 & 1.57 & $107.9 * * *$ \\
\hline Western Europe & -2.22 & 0.90 & 0.48 & 2.21 & 22.7 & -2.15 & 0.96 & 0.28 & 1.85 & 22.00 \\
\hline \multicolumn{11}{|c|}{ Panel D: Descriptive statistics for the Trading Volume estimates } \\
\hline Latin America (妏) & 6.58 & 1.00 & -2.70 & 13.64 & $991.6 * * *$ & 7.69 & 1.17 & -3.33 & 16.83 & $215.7 * * *$ \\
\hline Asian Pacific Emerging (†, 拝) & 4.53 & 1.12 & 0.28 & 1.99 & $19716^{* * *}$ & 5.54 & 0.70 & -0.84 & 5.92 & $2444.6^{* * *}$ \\
\hline Asian Pacific Developed ( & 8.54 & 0.96 & -1.02 & 6.46 & $18076 * * *$ & 9.65 & 0.57 & -9.14 & 113.30 & $182.36 * * *$ \\
\hline 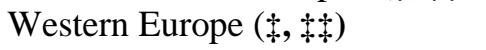 & 9.96 & 0.72 & -4.36 & 28.37 & $9627.2 * * *$ & 10.31 & 0.44 & -11.81 & 196.91 & $316.6 * * *$ \\
\hline
\end{tabular}

Note: Q-stat(20) denotes the Ljung-Box statistics for up to twentieth order serial correlation. *, ** and *** denote the serial correlation up to lag 20 is significant at $10 \%$, $5 \%$ and $1 \%$ significance level, respectively. Further, $¥$ and $¥$ 位dicate the linear trend and quadratic trend are significant at 5\% significance level, respectively. 
Table 2b: Descriptive Statistics for the Realized measures and trading volume of stock markets

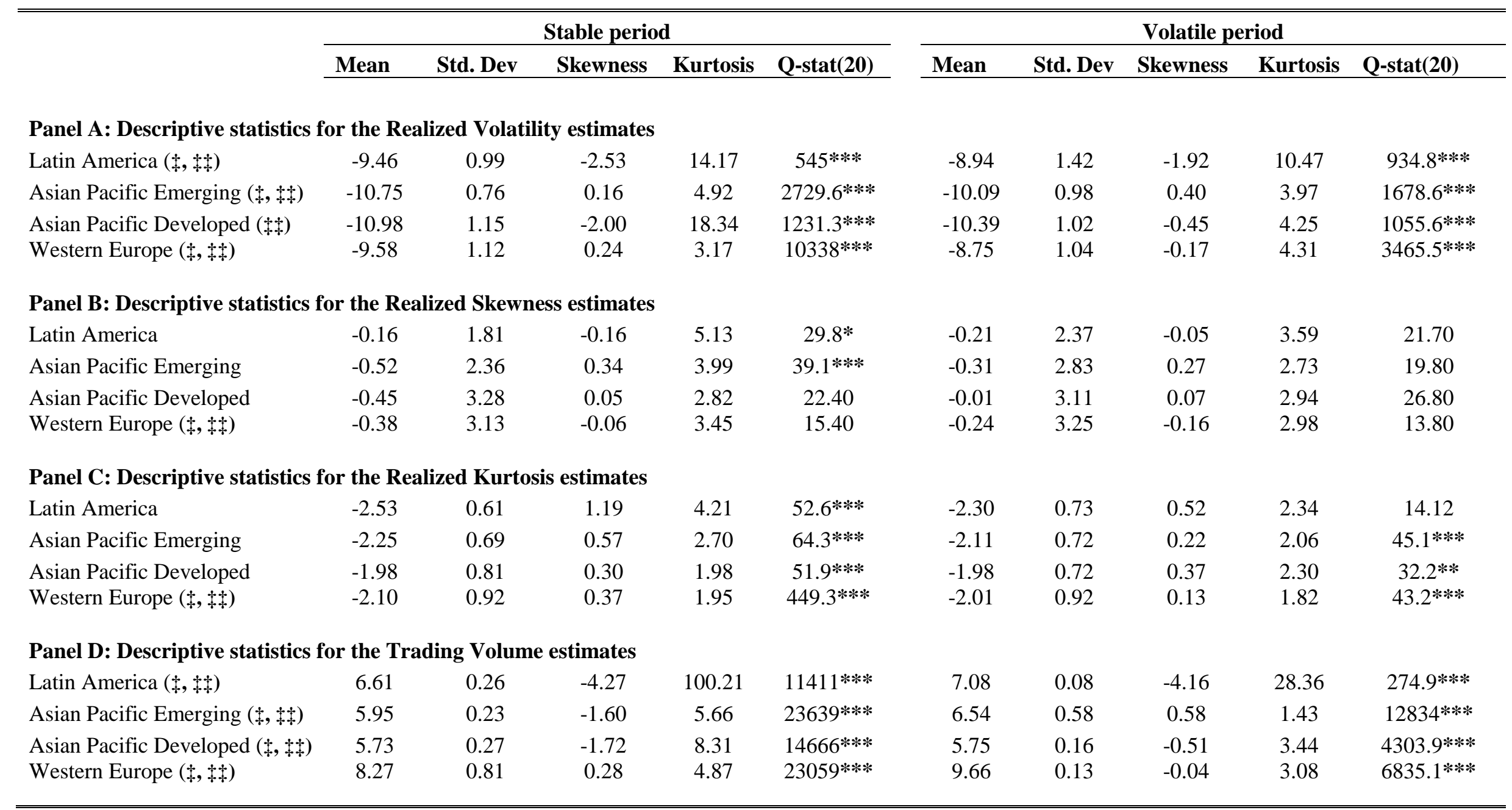

Note: Q-stat(20) denotes the Ljung-Box statistics for up to twentieth order serial correlation; *, ** and *** denote the serial correlation up to lag 20 is significant at $10 \%$, $5 \%$ and $1 \%$ significance level, respectively. Further, $¥$ and $¥+$ indicate the linear trend and quadratic trend are significant at $5 \%$ significance level, respectively. 
Table 3: Multivariate degree of fractional integration and optimal lag order

\begin{tabular}{|c|c|c|c|c|c|c|c|c|c|c|}
\hline \multicolumn{11}{|c|}{ Panel A: Multivariate degree of fractional integration in Foreign Exchange markets } \\
\hline \multirow[b]{2}{*}{ Periods } & \multicolumn{2}{|c|}{ Realized Volatility } & \multicolumn{2}{|c|}{ Realized Skewness } & \multicolumn{2}{|c|}{ Realized Kurtosis } & \multicolumn{2}{|c|}{ Volume } & \multicolumn{2}{|c|}{ Optimal lag } \\
\hline & Stable & Volatile & Stable & Volatile & Stable & Volatile & Stable & Volatile & Stable & Volatile \\
\hline \multirow[t]{2}{*}{ Latin America } & $0.45^{* * *}$ & $0.41 * * *$ & 0.01 & 0.01 & $0.26 * * *$ & $0.23 * * *$ & $0.38 * * *$ & $0.43 * * *$ & 2 & 2 \\
\hline & $(14.71)$ & (11.16) & $(0.22)$ & $(0.29)$ & $(7.64)$ & $(5.54)$ & (12.91) & $(10.72)$ & & \\
\hline Asian Pacific Emerging & $0.59 * * *$ & $0.67 * * *$ & $0.15^{* * *}$ & $0.14^{* * *}$ & $0.32 * * *$ & $0.36^{* * *}$ & $0.51^{* * *}$ & $0.48^{* * *}$ & 2 & 1 \\
\hline \multirow[t]{2}{*}{ Asian Pacific Developed } & $0.35 * * *$ & $0.40 * * *$ & -0.01 & $0.11^{* *}$ & $0.28 * * *$ & $0.20 * * *$ & $0.45^{* * *}$ & $0.50 * * *$ & 3 & 2 \\
\hline & (11.31) & (11.92) & $(-0.30)$ & $(2.21)$ & $(9.08)$ & $(5.68)$ & (14.09) & $(13.81)$ & & \\
\hline \multirow[t]{2}{*}{ Western Europe } & $0.41^{* * *}$ & $0.52^{* * *}$ & 0.00 & 0.05 & $0.14^{* * *}$ & $0.22 * * *$ & $0.66^{* * *}$ & $0.54 * * *$ & 6 & 2 \\
\hline & $(13.84)$ & $(15.01)$ & $(-0.02)$ & $(0.94)$ & $(4.32)$ & $(4.67)$ & $(17.73)$ & (14.49) & & \\
\hline \multicolumn{11}{|c|}{ Panel B: Multivariate degree of fractional integration in Stock markets } \\
\hline \multirow[t]{2}{*}{ Latin America } & $0.36^{* * *}$ & $0.45^{* * *}$ & $-0.08^{* *}$ & -0.05 & $0.14 * * *$ & $0.15^{* * *}$ & $0.49 * * *$ & $0.50 * * *$ & 2 & 2 \\
\hline & $(13.47)$ & $(10.67)$ & $(-2.05)$ & $(-1.33)$ & $(3.34)$ & $(3.25)$ & (14.15) & (9.59) & & \\
\hline \multirow[t]{2}{*}{ Asian Pacific Emerging } & $0.34^{* * *}$ & $0.54^{* * *}$ & $0.07 *$ & $0.08 *$ & $0.18^{* * *}$ & $0.27^{* * *}$ & $0.76^{* * *}$ & $0.91 * * *$ & 2 & 1 \\
\hline & (11.02) & (13.57) & (1.79) & $(1.87)$ & $(5.57)$ & $(5.70)$ & $(18.24)$ & (19.90) & & \\
\hline \multirow[t]{2}{*}{ Asian Pacific Developed } & $0.38^{* * *}$ & $0.51^{* * *}$ & $0.08 *$ & -0.01 & $0.19 * * *$ & $0.23^{* * *}$ & $0.48^{* * *}$ & $0.68 * * *$ & 3 & 2 \\
\hline & (10.92) & $(14.81)$ & $(1.97)$ & $(-0.29)$ & $(4.76)$ & $(4.82)$ & (13.12) & (16.91) & & \\
\hline \multirow[t]{2}{*}{ Western Europe } & $0.59 * * *$ & $0.67 * * *$ & 0.00 & 0.05 & $0.30 * * *$ & $0.20^{* * *}$ & $0.63^{* * *}$ & $0.75 * * *$ & 6 & 2 \\
\hline & (17.99) & (17.74) & $(0.10)$ & (1.32) & (7.13) & $(4.57)$ & (18.17) & (16.24) & & \\
\hline
\end{tabular}

Note: $* * *$ and $* * *$ denote that degree of fractional integration is significant at $10 \%, 5 \%$ and $1 \%$ significance level, respectively. The $z$-statistics are reported in parentheses. Note that we include both stock and FX markets of a region in one FIVAR system so the optimal lag reported for Panels A and B are the same. 
Table 4: Spillover from Trading Volume to realized measures

Panel A: Spillover from the Trading Volume of Foreign Exchange market

\begin{tabular}{|c|c|c|c|c|c|c|c|c|c|c|c|c|}
\hline & \multicolumn{6}{|c|}{ Foreign Exchange markets } & \multicolumn{6}{|c|}{ Stock markets } \\
\hline & \multicolumn{2}{|c|}{$\mathbf{R V}$} & \multicolumn{2}{|c|}{ RS } & \multicolumn{2}{|c|}{ RK } & \multicolumn{2}{|c|}{$\mathbf{R V}$} & \multicolumn{2}{|c|}{ RS } & \multicolumn{2}{|c|}{ RK } \\
\hline & $\mathrm{S}$ & $\mathbf{V}$ & $\mathrm{S}$ & $\mathbf{V}$ & $\mathrm{S}$ & $\mathbf{V}$ & $\mathrm{S}$ & $\mathbf{V}$ & $\mathrm{S}$ & $\mathbf{V}$ & $\mathrm{S}$ & $\mathbf{V}$ \\
\hline Latin America & $\oplus$ & $\oplus$ & $\bullet$ & $\bullet$ & $\theta$ & $\Theta$ & $\oplus$ & $\oplus$ & $\bullet$ & $\bullet$ & $\bullet$ & $\bullet$ \\
\hline Asian Pacific Emerging & $\oplus$ & $\oplus$ & $\bullet$ & $\bullet$ & $\theta$ & $\Theta$ & $\oplus$ & $\oplus$ & $\bullet$ & $\bullet$ & $\bullet$ & $\bullet$ \\
\hline Asian Pacific Developed & $\oplus$ & $\oplus$ & $\bullet$ & $\bullet$ & $\bullet$ & $\bullet$ & $\oplus$ & $\oplus$ & $\bullet$ & $\bullet$ & $\bullet$ & $\bullet$ \\
\hline West Europe Developed & $\oplus$ & $\oplus$ & $\bullet$ & $\bullet$ & $\bullet$ & $\bullet$ & $\bullet$ & $\bullet$ & $\bullet$ & $\bullet$ & $\bullet$ & $\bullet$ \\
\hline
\end{tabular}

Panel B: Spillover from the Trading Volume of Stock market

\begin{tabular}{|c|c|c|c|c|c|c|c|c|c|c|c|}
\hline Latin America & $\bullet$ & $\bullet$ & $\bullet$ & $\bullet$ & $\bullet$ & $\bullet$ & $\oplus$ & $\oplus$ & $\bullet$ & $\bullet$ & $\bullet$ \\
\hline Asian Pacific Emerging & $\bullet$ & $\oplus$ & $\bullet$ & $\oplus$ & $\bullet$ & $\oplus$ & $\oplus$ & $\oplus$ & $\bullet$ & $\bullet$ & $\bullet$ \\
\hline Asian Pacific Developed & $\bullet$ & $\oplus$ & $\bullet$ & $\bullet$ & $\bullet$ & $\bullet$ & $\oplus$ & $\oplus$ & $\bullet$ & $\bullet$ & $\bullet$ \\
\hline West Europe Developed & $\bullet$ & $\oplus$ & $\bullet$ & $\bullet$ & $\bullet$ & $\bullet$ & $\oplus$ & $\oplus$ & $\bullet$ & $\bullet$ & $\bullet$ \\
\hline
\end{tabular}

Notes: RV, RS, $\overline{\overline{\mathbf{R K}} \text { and Volume denote realized volatility, realized skewness, realized kurtosis and trading volume, respectively. } \mathbf{S} \text { and } \mathbf{V} \text { denotes the Stable and }}$ Volatile period, respectively. $\oplus$ denotes the spillover is positively significant. $\Theta$ denotes the spillover is negatively significant. $\bullet$ denotes the spillover is insignificant. We make conclusion about the significance of spillover effect using the asymptotic 95\% confidence interval of the generalized impulse response in FIVAR derived in Do et al. (2013b), (see Eq. (12)). 
Table 5: Spillover from Realized Volatility to other realized measures and Trading Volume

\begin{tabular}{|c|c|c|c|c|c|c|c|c|c|c|c|c|}
\hline & \multicolumn{6}{|c|}{ Foreign Exchange markets } & \multicolumn{6}{|c|}{ Stock markets } \\
\hline & \multicolumn{2}{|c|}{ RS } & \multicolumn{2}{|c|}{ RK } & \multicolumn{2}{|c|}{ Volume } & \multicolumn{2}{|c|}{ RS } & \multicolumn{2}{|c|}{ RK } & \multicolumn{2}{|c|}{ Volume } \\
\hline & $\mathbf{S}$ & $\mathbf{V}$ & $\mathrm{S}$ & $\mathbf{V}$ & $\mathbf{S}$ & $\mathbf{V}$ & $\mathrm{S}$ & $\mathbf{V}$ & S & $\mathbf{V}$ & $\mathbf{S}$ & $\mathbf{V}$ \\
\hline Latin America & $\bullet$ & $\bullet$ & $\oplus$ & $\bullet$ & $\oplus$ & $\oplus$ & $\bullet$ & $\bullet$ & $\bullet$ & $\bullet$ & $\bullet$ & $\bullet$ \\
\hline Asian Pacific Emerging & $\bullet$ & - & $\oplus$ & $\oplus$ & $\oplus$ & $\oplus$ & $\bullet$ & $\bullet$ & - & $\bullet$ & $\bullet$ & $\bullet$ \\
\hline Asian Pacific Developed & $\bullet$ & $\bullet$ & $\oplus$ & $\oplus$ & $\oplus$ & $\oplus$ & $\bullet$ & $\bullet$ & $\bullet$ & $\oplus$ & $\oplus$ & $\oplus$ \\
\hline West Europe Developed & $\bullet$ & $\bullet$ & $\oplus$ & $\oplus$ & $\oplus$ & $\oplus$ & $\bullet$ & $\bullet$ & $\bullet$ & $\bullet$ & $\bullet$ & $\bullet$ \\
\hline \multicolumn{13}{|c|}{ Panel B: Spillover from the Realized Volatility of Stock market } \\
\hline Latin America & $\bullet$ & $\bullet$ & $\Theta$ & $\Theta$ & $\oplus$ & $\oplus$ & $\bullet$ & $\bullet$ & $\bullet$ & $\bullet$ & $\oplus$ & $\oplus$ \\
\hline Asian Pacific Emerging & $\bullet$ & $\bullet$ & $\bullet$ & $\oplus$ & $\oplus$ & $\oplus$ & $\bullet$ & $\bullet$ & $\oplus$ & $\oplus$ & $\bullet$ & $\oplus$ \\
\hline Asian Pacific Developed & $\bullet$ & $\bullet$ & $\bullet$ & $\bullet$ & $\oplus$ & $\oplus$ & $\bullet$ & $\bullet$ & $\oplus$ & $\oplus$ & $\oplus$ & $\oplus$ \\
\hline West Europe Developed & $\bullet$ & $\bullet$ & $\bullet$ & $\bullet$ & $\oplus$ & $\oplus$ & $\bullet$ & $\bullet$ & $\oplus$ & $\oplus$ & $\oplus$ & $\oplus$ \\
\hline
\end{tabular}

Notes: RV, RS, RK and Volume denote realized volatility, realized skewness, realized kurtosis and trading volume, respectively. $\mathbf{S}$ and $\mathbf{V}$ denotes the Stable and Volatile period, respectively. $\oplus$ denotes the spillover is positively significant. $\Theta$ denotes the spillover is negatively significant. $\bullet$ denotes the spillover is insignificant. The significance of a spillover effect is based on the asymptotic 95\% confidence interval of the generalized impulse response in the FIVAR derived in Do et al. (2013b), (see Eq. (12)). 
Table 6: Spillover from Realized Skewness to other realized measures and Trading Volume

\begin{tabular}{|c|c|c|c|c|c|c|c|c|c|c|c|c|}
\hline & \multicolumn{6}{|c|}{ Foreign Exchange markets } & \multicolumn{6}{|c|}{ Stock markets } \\
\hline & \multicolumn{2}{|c|}{$\mathbf{R V}$} & \multicolumn{2}{|c|}{ RK } & \multicolumn{2}{|c|}{ Volume } & \multicolumn{2}{|c|}{$\mathbf{R V}$} & \multicolumn{2}{|c|}{ RK } & \multicolumn{2}{|c|}{ Volume } \\
\hline & $\mathrm{S}$ & $\mathbf{V}$ & $\mathrm{S}$ & $\mathbf{V}$ & S & $\mathbf{V}$ & $\mathrm{S}$ & $\mathbf{V}$ & $\mathbf{S}$ & $\mathbf{V}$ & S & $\mathbf{V}$ \\
\hline Latin America & $\Theta$ & $\Theta$ & $\bullet$ & $\bullet$ & $\bullet$ & $\bullet$ & $\Theta$ & $\Theta$ & $\bullet$ & $\bullet$ & $\bullet$ & • \\
\hline Asian Pacific Emerging & $\bullet$ & $\bullet$ & $\oplus$ & $\bullet$ & $\bullet$ & $\oplus$ & $\bullet$ & $\theta$ & $\bullet$ & $\bullet$ & $\bullet$ & $\oplus$ \\
\hline Asian Pacific Developed & $\bullet$ & $\oplus$ & $\bullet$ & $\bullet$ & $\bullet$ & $\oplus$ & $\bullet$ & $\oplus$ & $\bullet$ & $\bullet$ & $\bullet$ & $\bullet$ \\
\hline West Europe Developed & $\bullet$ & $\Theta$ & $\bullet$ & $\bullet$ & $\bullet$ & $\bullet$ & $\bullet$ & $\theta$ & $\bullet$ & • & • & • \\
\hline
\end{tabular}

Panel B: Spillover from the Realized Skewness of Stock market

\begin{tabular}{|c|c|c|c|c|c|c|c|c|c|c|c|c|}
\hline Latin America & $\oplus$ & $\oplus$ & $\oplus$ & $\bullet$ & $\bullet$ & $\oplus$ & $\oplus$ & $\oplus$ & $\bullet$ & $\bullet$ & $\bullet$ & • \\
\hline Asian Pacific Emerging & $\bullet$ & $\bullet$ & $\bullet$ & $\bullet$ & $\bullet$ & $\Theta$ & $\oplus$ & $\oplus$ & $\bullet$ & $\bullet$ & $\bullet$ & $\bullet$ \\
\hline Asian Pacific Developed & $\bullet$ & $\oplus$ & $\bullet$ & $\bullet$ & $\oplus$ & $\oplus$ & $\oplus$ & $\oplus$ & $\bullet$ & $\bullet$ & $\bullet$ & $\oplus$ \\
\hline West Europe Developed & $\bullet$ & $\oplus$ & $\bullet$ & $\bullet$ & $\bullet$ & $\bullet$ & $\oplus$ & $\oplus$ & $\bullet$ & $\bullet$ & $\bullet$ & $\bullet$ \\
\hline
\end{tabular}

Notes: RV, RS, RK and Volume denote realized volatility, realized skewness, realized kurtosis and trading volume, respectively. $\mathbf{S}$ and $\mathbf{V}$ denotes the Stable and Volatile period, respectively. $\oplus$ denotes the spillover is positively significant. $\Theta$ denotes the spillover is negatively significant. $\bullet$ denotes the spillover is insignificant. The significance of a spillover effect is based on the asymptotic 95\% confidence interval of the generalized impulse response in the FIVAR derived in Do et al. (2013b), (see Eq. (12)). 
Table 7: Spillover from Realized Kurtosis to other realized measures and Trading Volume

\begin{tabular}{|c|c|c|c|c|c|c|c|c|c|c|c|c|}
\hline \multicolumn{13}{|c|}{ Panel A: Spillover from the Realized Kurtosis of Foreign Exchange market } \\
\hline & \multicolumn{6}{|c|}{ Foreign Exchange markets } & \multicolumn{6}{|c|}{ Stock markets } \\
\hline & \multicolumn{2}{|c|}{$\mathbf{R V}$} & \multicolumn{2}{|c|}{ RS } & \multicolumn{2}{|c|}{ Volume } & \multicolumn{2}{|c|}{$\mathbf{R V}$} & \multicolumn{2}{|c|}{ RS } & \multicolumn{2}{|c|}{ Volume } \\
\hline & $\mathbf{S}$ & $\mathbf{V}$ & $\mathbf{S}$ & $\mathbf{V}$ & $\mathbf{S}$ & $\mathbf{V}$ & $\mathbf{S}$ & $\mathbf{V}$ & S & $\mathbf{V}$ & S & $\mathbf{V}$ \\
\hline Latin America & $\bullet$ & $\bullet$ & $\bullet$ & $\bullet$ & $\theta$ & $\Theta$ & $\theta$ & $\bullet$ & $\bullet$ & $\bullet$ & $\bullet$ & $\oplus$ \\
\hline Asian Pacific Emerging & $\oplus$ & $\oplus$ & $\oplus$ & $\bullet$ & $\bullet$ & $\theta$ & $\bullet$ & $\bullet$ & $\bullet$ & $\bullet$ & $\bullet$ & $\oplus$ \\
\hline Asian Pacific Developed & $\oplus$ & $\oplus$ & $\bullet$ & $\bullet$ & $\bullet$ & $\bullet$ & $\bullet$ & $\bullet$ & $\bullet$ & $\bullet$ & $\bullet$ & $\bullet$ \\
\hline West Europe Developed & $\oplus$ & $\oplus$ & $\bullet$ & $\bullet$ & • & $\bullet$ & $\bullet$ & $\bullet$ & $\bullet$ & $\bullet$ & • & $\bullet$ \\
\hline \multicolumn{13}{|c|}{ Panel B: Spillover from the Realized Kurtosis of Stock market } \\
\hline Latin America & $\bullet$ & $\bullet$ & $\bullet$ & $\bullet$ & $\bullet$ & $\bullet$ & $\oplus$ & $\bullet$ & $\bullet$ & $\bullet$ & $\bullet$ & $\bullet$ \\
\hline Asian Pacific Emerging & $\oplus$ & $\bullet$ & $\bullet$ & $\bullet$ & $\bullet$ & $\bullet$ & $\oplus$ & $\oplus$ & $\bullet$ & $\bullet$ & $\bullet$ & $\oplus$ \\
\hline Asian Pacific Developed & $\bullet$ & $\bullet$ & $\bullet$ & $\bullet$ & $\bullet$ & $\bullet$ & $\oplus$ & $\oplus$ & $\bullet$ & $\bullet$ & $\bullet$ & $\bullet$ \\
\hline West Europe Developed & $\bullet$ & $\bullet$ & $\bullet$ & $\bullet$ & $\bullet$ & $\bullet$ & $\oplus$ & $\oplus$ & $\bullet$ & • & $\bullet$ & $\theta$ \\
\hline
\end{tabular}

Notes: RV, RS, RK and Volume denote realized volatility, realized skewness, realized kurtosis and trading volume, respectively. $\mathbf{S}$ and $\mathbf{V}$ denotes the Stable and Volatile period, respectively. $\oplus$ denotes the spillover is positively significant. $\Theta$ denotes the spillover is negatively significant. $\bullet$ denotes the spillover is insignificant. The significance of a spillover effect is based on the asymptotic 95\% confidence interval of the generalized impulse response in the FIVAR derived in Do et al. (2013b), (see Eq. (12)). 
Table 8: Non-linear Granger Causality from Trading Volume to Realized Higher Moments

\begin{tabular}{|c|c|c|c|c|c|c|c|c|c|c|c|c|}
\hline \multicolumn{13}{|c|}{ Panel A: Causality from Trading Volume of Foreign Exchange market } \\
\hline \multirow{3}{*}{ (Causality to) } & \multicolumn{6}{|c|}{ Foreign Exchange markets } & \multicolumn{4}{|c|}{ Stock markets } & \multirow{2}{*}{\multicolumn{2}{|c|}{ RK }} \\
\hline & \multicolumn{2}{|c|}{$\mathbf{R V}$} & \multicolumn{2}{|c|}{ RS } & \multicolumn{2}{|c|}{ RK } & \multicolumn{2}{|c|}{$\mathbf{R V}$} & \multicolumn{2}{|c|}{ RS } & & \\
\hline & Stable & Volatile & Stable & Volatile & Stable & Volatile & Stable & Volatile & Stable & Volatile & Stable & Volatile \\
\hline Latin America & 1.696 & 1.464 & -0.371 & 1.148 & 0.454 & -0.874 & 1.501 & 0.428 & 1.702 & -0.166 & 0.44 & -0.64 \\
\hline Asian Pacific Emerging & -0.306 & 0.021 & 0.045 & 1.603 & 0.026 & 0.64 & 0.578 & 0.83 & -0.322 & -0.238 & 0.772 & -0.17 \\
\hline Asian Pacific Developed & -0.589 & 0.538 & -0.593 & -1.127 & -0.988 & -0.465 & 1.061 & 2.002 & 0.03 & -0.808 & -1.071 & 0.594 \\
\hline West Europe Developed & 1.698 & 1.362 & 1.177 & -0.364 & 1.404 & -0.505 & -0.262 & 2.088 & -2.109 & -0.489 & -1.24 & 0.157 \\
\hline
\end{tabular}

Panel B: Causality from Trading Volume of Stock market

\begin{tabular}{|c|c|c|c|c|c|c|c|c|c|c|c|c|}
\hline Latin America & -0.208 & 0.074 & 1.767 & 0.568 & 1.15 & -1.312 & -0.064 & 1.203 & 0.498 & 1.043 & 0.449 & 0.919 \\
\hline Asian Pacific Emerging & -0.587 & -0.18 & -0.133 & 1.154 & -1.391 & -0.668 & -0.927 & -1.283 & -1.737 & -1.859 & -0.915 & -1.037 \\
\hline Asian Pacific Developed & 1.715 & -0.435 & -0.808 & 0.703 & -1.724 & 0.654 & 2.669 & 0.033 & -0.093 & -0.839 & -0.291 & -0.69 \\
\hline West Europe Developed & -0.962 & 2.05 & -1.949 & -0.821 & -0.356 & -0.455 & 0.149 & 0.863 & -1.754 & -1.482 & 0.317 & -0.553 \\
\hline
\end{tabular}

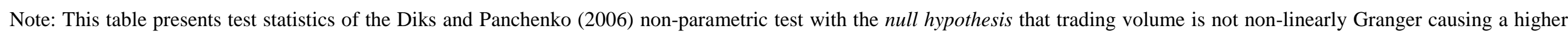

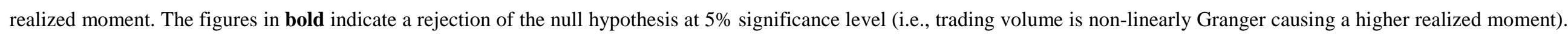
$\mathbf{R V}, \mathbf{R S}$ and RK denote the realized volatility, skewness and kurtosis, respectively. 
Table 9: Non-linear Granger Causality from Realized Higher Moments to Trading volume

\begin{tabular}{|c|c|c|c|c|c|c|c|c|c|c|c|c|}
\hline \multicolumn{13}{|c|}{ Panel A: Causality to Trading Volume of Foreign Exchange market } \\
\hline \multirow{3}{*}{ (Causality from) } & \multicolumn{6}{|c|}{ Foreign Exchange markets } & \multicolumn{6}{|c|}{ Stock markets } \\
\hline & \multicolumn{2}{|c|}{$\mathbf{R V}$} & \multicolumn{2}{|c|}{ RS } & \multicolumn{2}{|c|}{ RK } & \multicolumn{2}{|c|}{$\mathbf{R V}$} & \multicolumn{2}{|c|}{ RS } & \multicolumn{2}{|c|}{ RK } \\
\hline & Stable & Volatile & Stable & Volatile & Stable & Volatile & Stable & Volatile & Stable & Volatile & Stable & Volatile \\
\hline Latin America & 2.395 & 0.95 & -1.304 & -0.144 & -0.579 & 0.499 & -0.456 & -2.313 & 0.516 & -0.151 & -0.443 & 0.055 \\
\hline Asian Pacific Emerging & -0.507 & -0.319 & -2.065 & -0.021 & -0.719 & -0.18 & 0.019 & -0.446 & -1.291 & -0.242 & 0.707 & -0.398 \\
\hline Asian Pacific Developed & -0.109 & 0.034 & -0.914 & -0.497 & -0.169 & 0.616 & 2.297 & 1.959 & 0.292 & -3.523 & -0.624 & -1.609 \\
\hline West Europe Developed & -0.352 & 1.739 & 0.433 & 1.244 & 0.51 & -0.417 & 1.27 & 5.01 & -2.408 & 1.39 & -1.733 & 0.792 \\
\hline
\end{tabular}

\section{Panel B: Causality to Trading Volume of Stock market}

\begin{tabular}{|c|c|c|c|c|c|c|c|c|c|c|c|c|}
\hline Latin America & -0.848 & 0.612 & -1.325 & -0.946 & 0.183 & -0.246 & -0.749 & -0.222 & -1.511 & 0.313 & -0.885 & -0.511 \\
\hline Asian Pacific Emerging & -1.087 & -2.922 & 0.343 & -0.155 & 0.102 & -2.071 & -0.157 & -2.372 & 1.708 & -1.187 & 1.325 & 0.675 \\
\hline Asian Pacific Developed & -0.167 & -0.942 & -2.232 & -1.712 & -0.43 & 0.211 & 0.789 & 0.682 & -1.515 & -0.322 & -1.826 & -0.405 \\
\hline West Europe Developed & 1.627 & 0.114 & 1.652 & 1.558 & 1.438 & 1.099 & -0.712 & 1.163 & -1.519 & -0.866 & -0.943 & -0.511 \\
\hline
\end{tabular}

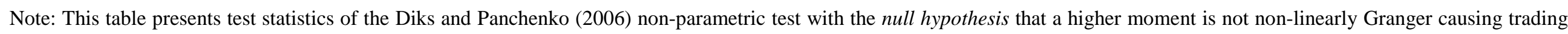

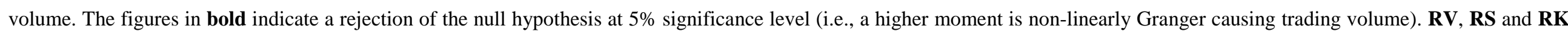
denote the realized volatility, skewness and kurtosis, respectively. 


\section{Figure 1: Dynamic inter-relationship among realized higher moments}

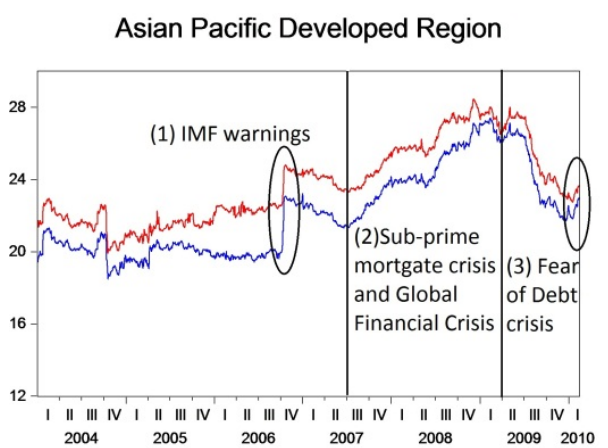

Western European Developed Region

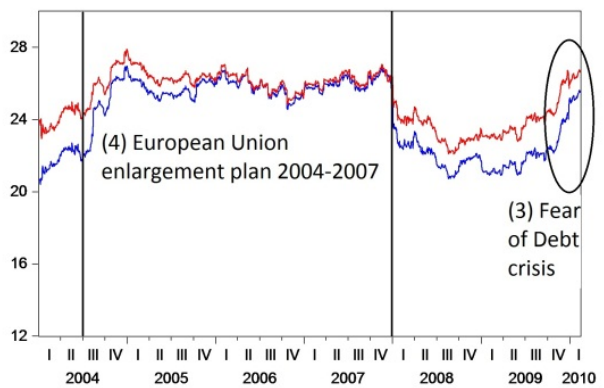

Asian Pacific Emerging Region

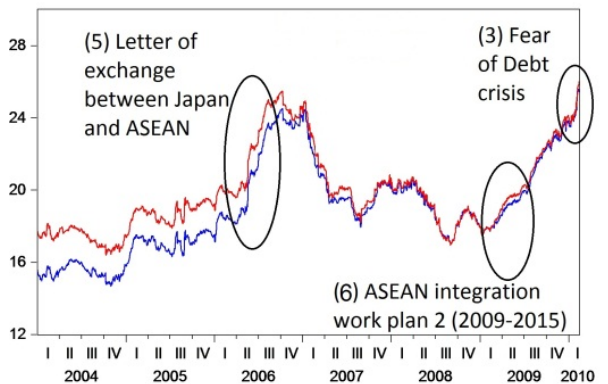

- Without controlling Volume impacts
After controlling Volume impacts

Notes:

(1) In October 2006, the International Monetary Fund (IMF) started warning Australian Banks about their fragilities, which causes almost immediately worries in Australian and other advanced markets in the Asia-Pacific. For example, Japan and Hong Kong were also affected because of the bad news.
(2) The subprime mortgage crisis started in the U.S around mid-2007 then spread globally as the Global Financial Crisis from QIV in 2008, which has caused one of the greatest global recessions in financial history.

(3) Fear of a European sovereign debt crisis has risen from late 2009 since many European countries faced a huge problem with budget deficits. Although it is analytically separate from the Global Financial Crisis in 2008, the two crises are linked because many European banks held assets in American banks, which were facing financial troubles.

(4) European enlargement plan from 2004 to 2007 led Western European developed countries to transfer large amounts of financial products (and structural funds) to less developed countries during that period.

(5) In March 2006, a Letter of Exchange was established between Japan and the Association of Southeast Asian Nations (ASEAN), which stated that Japan would provide a fund of $¥ 7.5$ billion to support ASEAN’s integration efforts, marking a new level of commitment towards regional integration in the Asia-Pacific region.

(6) In early 2009, ASEAN launched the Integration work plan 2 for the period from 2009 to 2015. The plan aims to narrow the development gap and increase the integration between ASEAN's members by allowing the free flow of goods/ services, investment capital and so on. 
Figure 2: Directional Spillover effects in the Asia Pacific Developed region Spillover from RV_FX

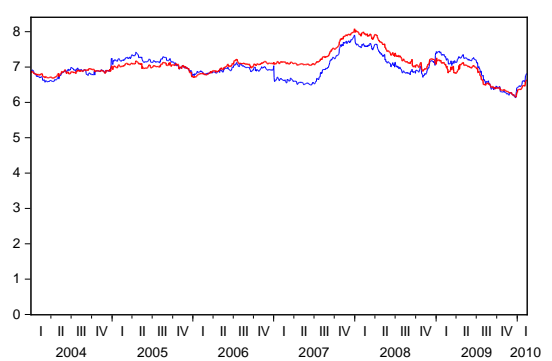

Spillover from RS_FX

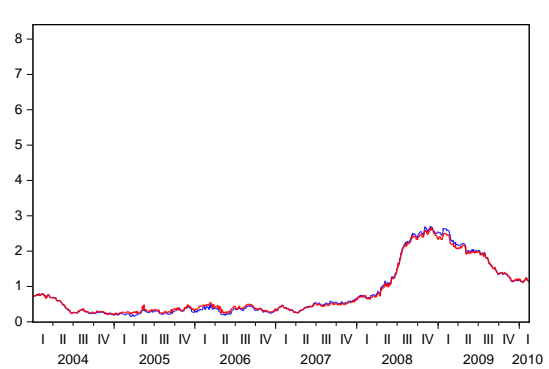

Spillover from RK_FX

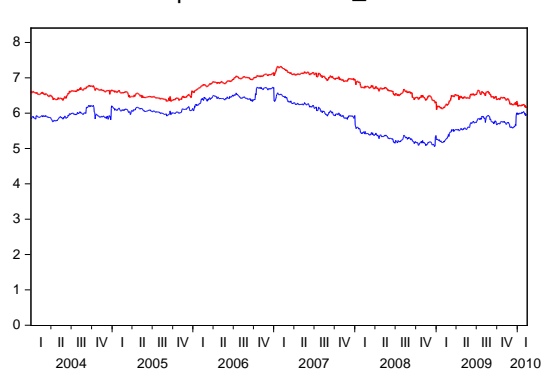

- Without controlling Volume impacts
- After controlling Volume impacts

Note: RV, RS, RK and Volume denote realized volatility, skewness, kurtosis and trading volume respectively.

Further, $\mathbf{F X}$ and ST denote the Foreign Exchange and stock markets, respectively.
Figure 3: Directional Spillover effects in the Western European Developed region

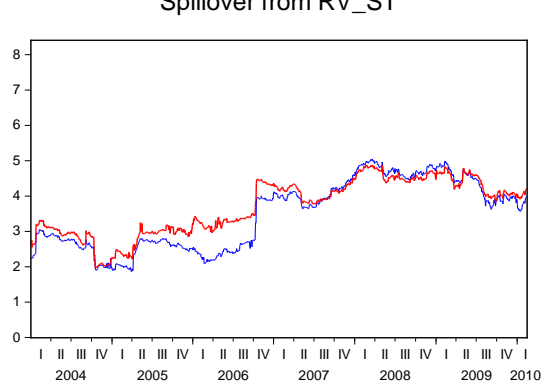

Spillover from RV FX

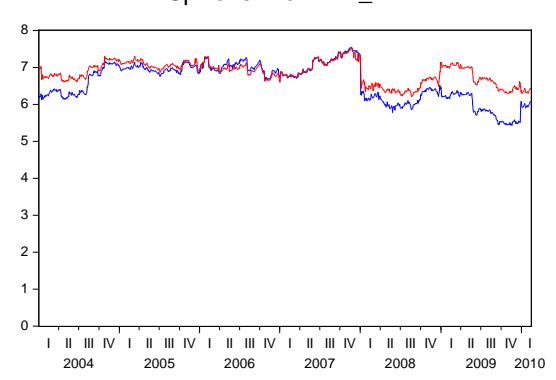

Spillover from RS_FX

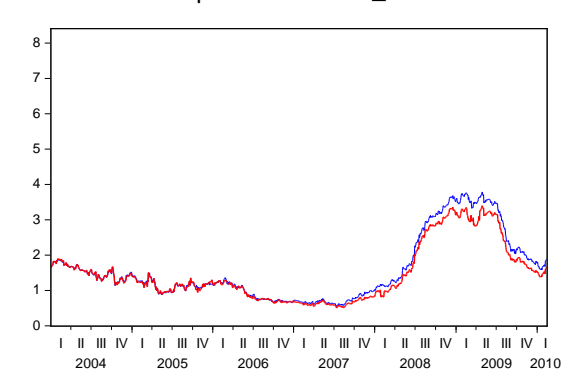

Spillover from RK_ST
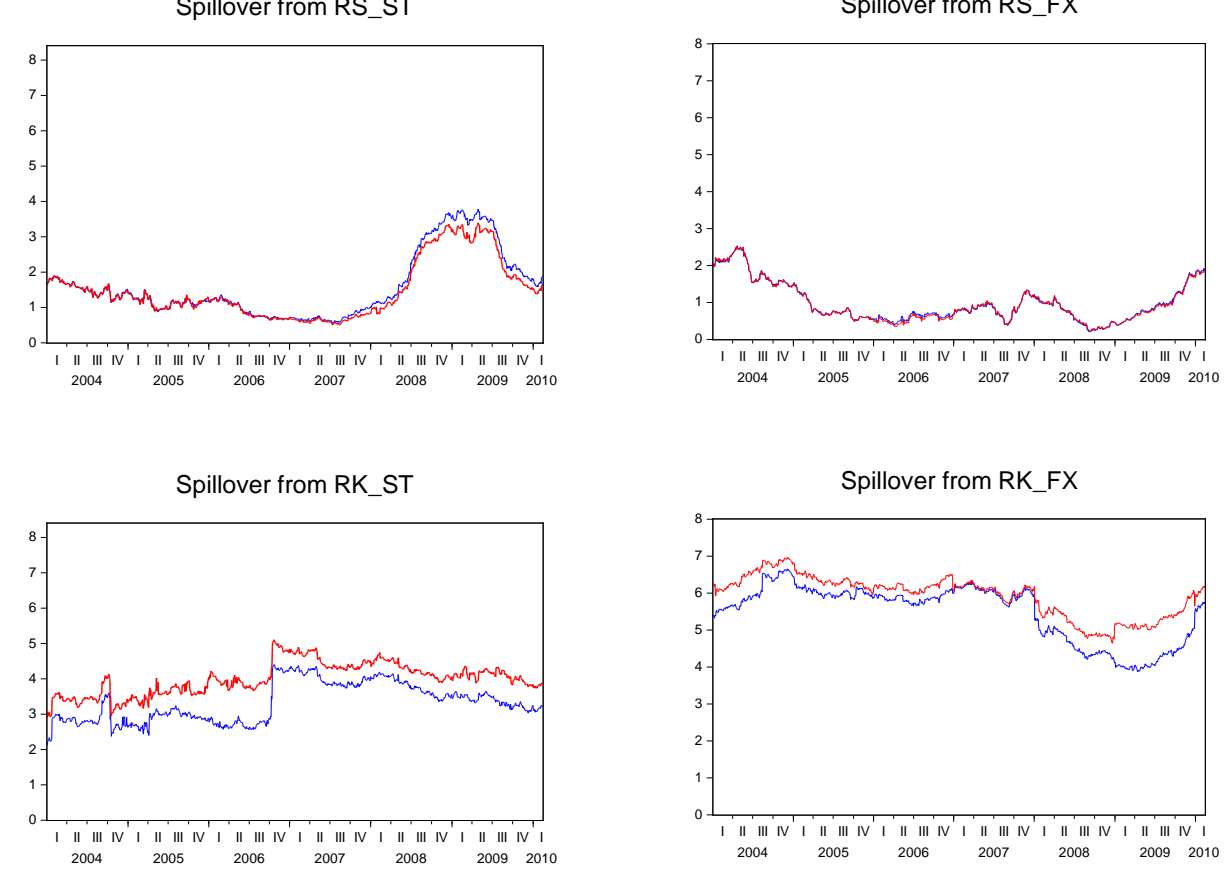

Spillover from RK FX

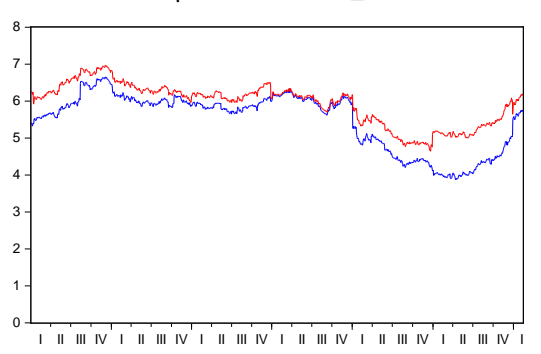

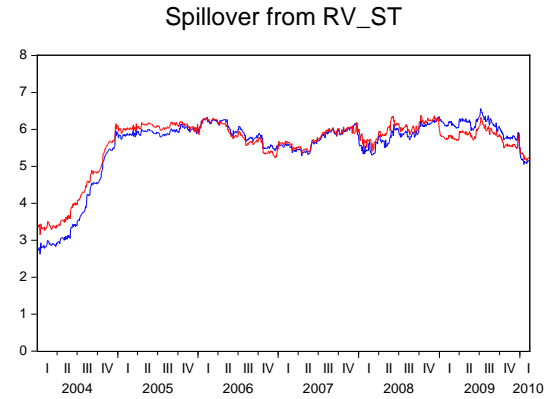

Spillover from RS_ST

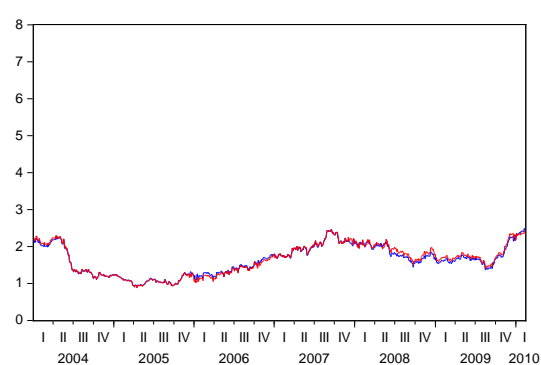

Spillover from RK_ST

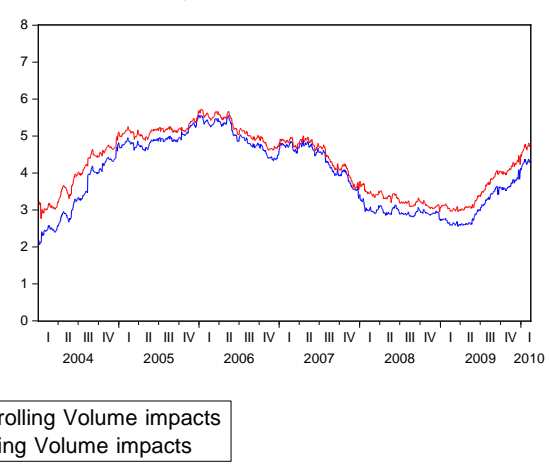

Note: RV, RS, RK and Volume denote realized volatility, skewness, kurtosis and trading volume respectively. Further, FX and ST denote the Foreign Exchange and stock markets, respectively. 
Figure 4: Directional Spillover effects in the Asia Pacific Emerging region

Spillover from RV_FX

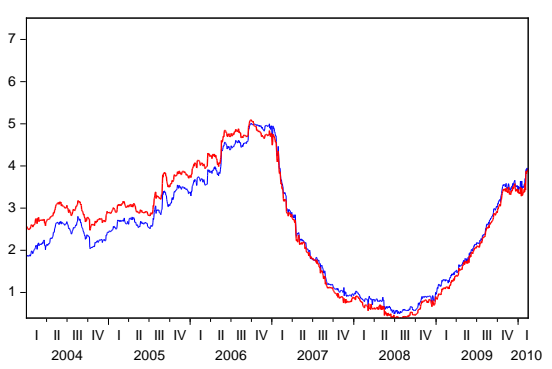

Spillover from RS_FX

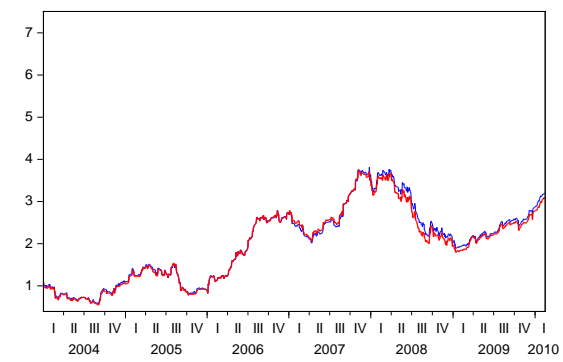

Spillover from RK_FX

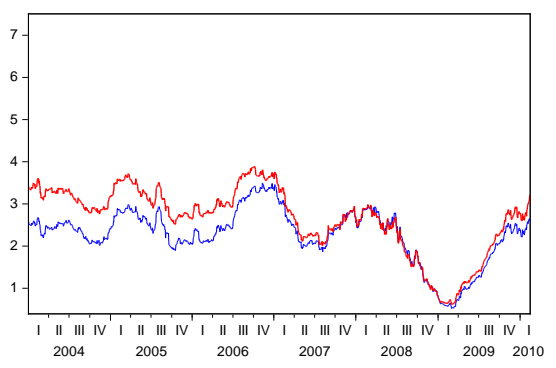

Spillover from RV ST

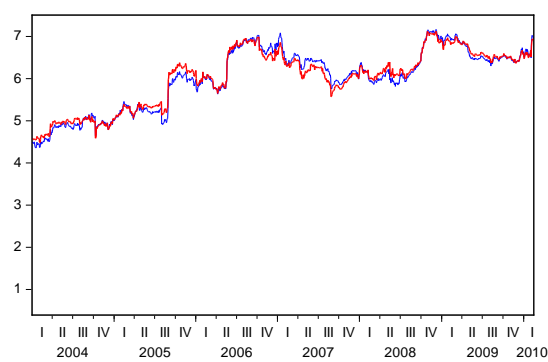

Spillover from RS ST

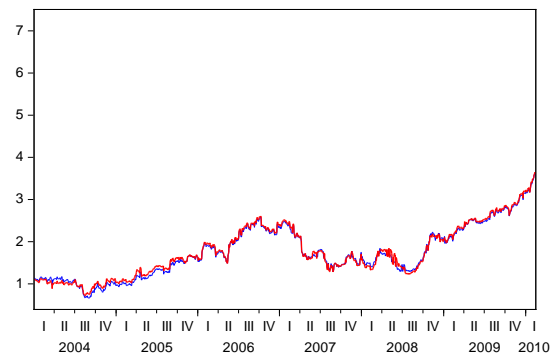

Spillover from RK_ST

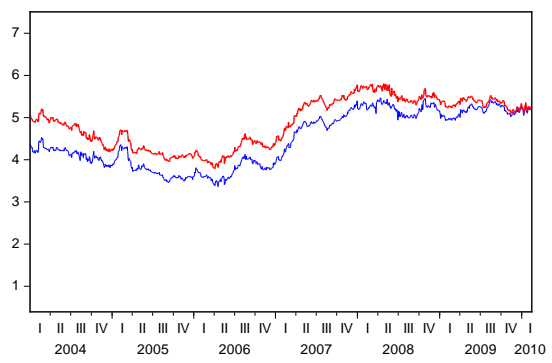

controlling Volume impacts

Note: RV, RS, RK and Volume denote realized volatility, skewness, kurtosis and trading volume respectively. Further, FX and ST denote the Foreign Exchange and stock markets, respectively.

Figure 5: Directional Spillover effects in the Latin American region

Spillover from RV FX

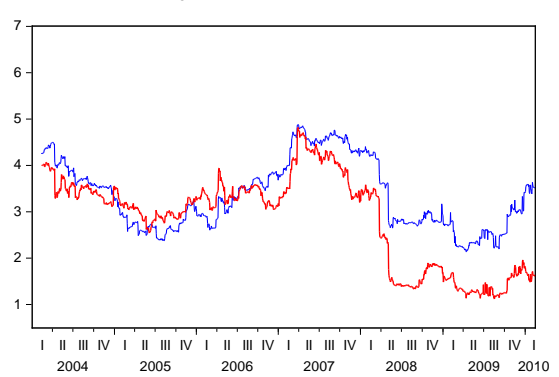

Spillover from RS FX

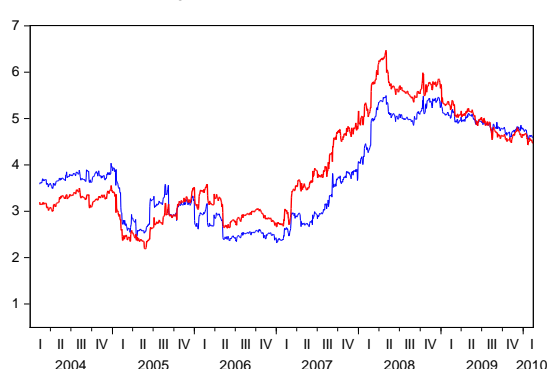

Spillover from RK_FX

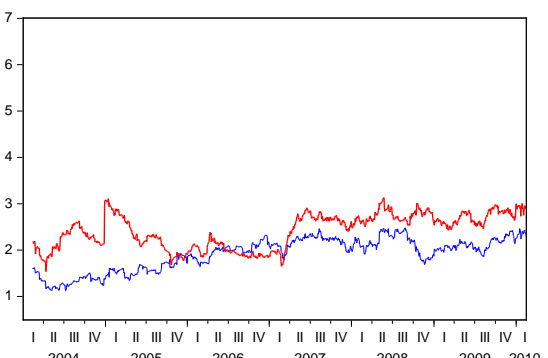

Spillover from RV ST

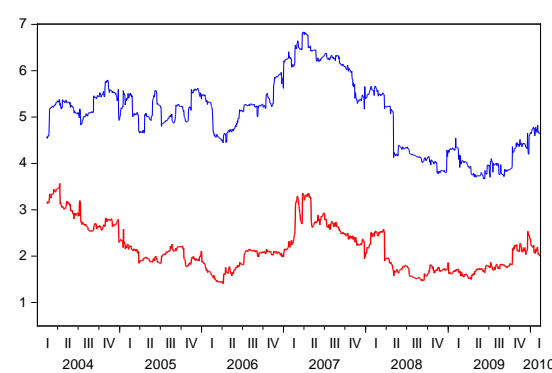

Spillover from RS ST

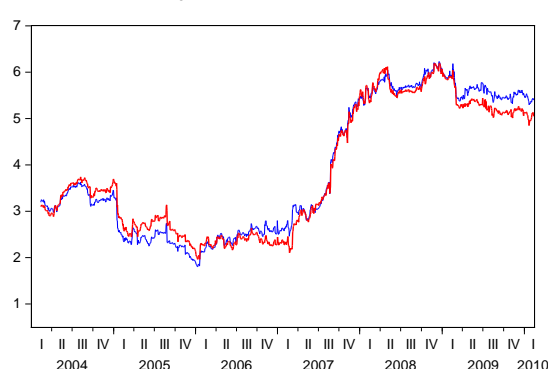

Spillover from RK_ST

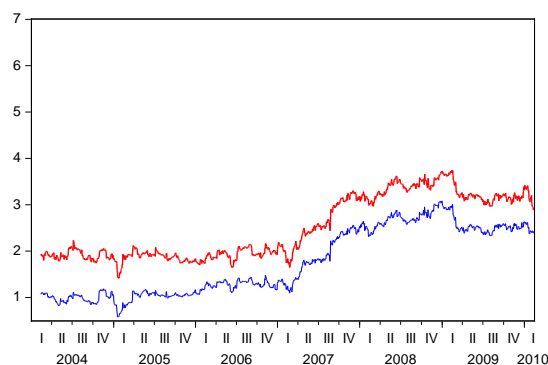

olling Volume impacts

Note: RV, RS, RK and Volume denote realized volatility, skewness, kurtosis and trading volume respectively. Further, $\mathbf{F X}$ and ST denote the Foreign Exchange and stock markets, respectively. 